\title{
The Influence of the Korean Wave on the Language of International Fans: Case Study of Algerian Fans
}

\author{
Batoul Touhami, Prof. Fawwaz Al-Abed Al-Haq \\ Yarmouk University, Irbid, Jordan
}

\begin{abstract}
The linguistic influence of the Korean Wave (Hallyu, which refers to the Korean pop and drama) on the language of International fans is that of a salient but not linguistically examined phenomenon. This study investigates the major aspects of this influence and the linguistic reasons behind its global prevalence. The practical part of this study is conducted on Algerian Hallyu fans from which a sample of 139 participants responded to the questionnaire used as a research instrument for achieving the goal of this study. Findings reveal that Hallyu influence is widely spread in Algeria, where by $98.5 \%$ of the participants declared the existence of this influence. This impact on participants' language starts from using Korean words in their daily discourse to using English words with an adapted Hallyu meaning and to naming phone contacts with the accurate Korean terms of kinship and endearment. Then, they start using linguistically odd inside jokes taken from Korean idols' and K-dramas' speech, employing Korean proverbs in their conversations, and gradually adopting a different pronunciation of some English sounds. Moreover, their language stands as a sample of Corpus Planning with two types: Modernization and Graphization. Some words are modernized in order to bridge the gap through Hallyu pals' communication with more precise words, while other words are graphitized for the sake of developing new terms or new meanings or to shorten long ones. This thesis contributes to the study of fandom language, generally, and to Hallyu language, specifically, as an aspect of Conversation Analysis (CA).
\end{abstract}

Keywords: the Korean Wave (Hallyu), International fans' language, conversation analysis, corpus planning, Algerian fans, linguistic influence

\section{Introduction}

This study examines the linguistic attitude of Algerian fans towards the Korean Wave. It aims at highlighting the major aspects of this kind of entertainment's influence on. Fandom conversation is an interesting issue that may contribute to the improvement of the domain of Conversation Analysis, which is the theoretical framework that will enable this study to fulfill its goal of analyzing fandom verbal interactions as a category of Secondary/Non-dominant Discourse with no wider status than inside the fandom.

\section{Fandom Language}

Fandom is a combination of the two words "fan" and "domain". "Fandom is the world of enthusiasts for some amusement or for some artist" (Oxford English Dictionaries, 2011).

Batoul Touhami, M.A., English Department, Yarmouk University, Irbid, Jordan.

Prof. Fawwaz Al-Abed Al-Haq, professor, Ph.D., English Department, Yarmouk University, Irbid, Jordan. 
There is no limit to the ways in which human beings league themselves together for self-identification, security, gain, amusement, worship, or any of the other purposes that are held in common; consequently there is no limit to the number and variety of speech communities that are to be found in a society. (Wardhaugh, 2002, p. 124)

Accordingly, fandom is one of the various speech communities whose language is that with specific characteristics.

Fandom language is a language that usually tackles all the aspects of the domain or the entertainment this fandom is dedicated to. Once a fandom community discusses these aspects, they demonstrate a unique language use that only they could explain its linguistic characteristics.

According to Fukunaga (2006), people hugely interested in foreign popular cultures will probably develop a critical attitude, cultural knowledge, and foreign language skills. People that have an identical tendency towards a kind of pleasure item have a characteristic language use. "In fandom, fans use specific language that people outside of their group might not understand and recognize; we call this specific language lexis" (Potayroi, 2014, p. 123).

Nowadays, technology of social media makes people catch on different kinds of entertainments, even from overseas. It is an idiosyncratic sort of conversation for every fandom community to have a distinct language with a distinct terminology, especially with the case of International fans by virtue of their being non-native speakers of the entertainment's language they are into. This linguistic fact makes a community of one-kind fans only intelligible among one another.

\section{The Korean Wave Definition}

The "Korean Wave" or Hallyu is an expression used to refer to the popularity of Korean entertainment, Korean pop (K-pop) and Korean drama (K-drama). According to Wikipedia, "K-pop is a music genre originating in South Korea that is characterized by a wide variety of audiovisual elements"; "K-drama refers to televised dramas in the Korean language, made in South Korea, mostly in a miniseries format (16-20 episodes), with distinctive features that set them apart from television series and soap operas made elsewhere" ("Korean Wave", n.d.). Choechoiblyeog (2017) declared that Hallyu fans reached more than 60 million all over the world, which makes them surpass South Korea's population. The number of fans in Africa and the Middle East was raised from 170.000 to 190.000 in 2017.

\section{International Fans}

International fans are Non-Korean fans whose native language is not Korean, yet they surpass the language barrier and show an obsession towards K-pop and K-drama. Algerian fans are a part of International fans of the Korean Wave who create their own environment whose language only they can speak.

\section{Hallyu Language}

As a Hallyu International fan from 2008, the researcher has noticed that pals dedicated to the Korean Wave have a unique language use. Their language is a mix of mother tongue (Algerian Arabic in the environment of the researcher) with Korean and English. They also use informal expressions through their talk like the utterance "aiish" to show annoyance or "assah" to express victory or satisfaction. Furthermore, their language on Social Networking Sites (SNS) is characteristically different from other online communities. A person can observe new lexis usage: some English words to which they add the sound "eu" at the end and some for which they change the sound $/ \mathrm{v} /$ to $/ \mathrm{b} /, / \mathrm{f} /$ to $/ \mathrm{p} /, / \mathrm{s} /$ to $/ \mathrm{J} /, / \theta /$ to $/ \mathrm{s} /$ and interchange between the sounds $/ \mathrm{l} /$ and $/ \mathrm{r} /$ the way Koreans do according to their language phonological characteristics. This influence on 
International fans' pronunciation of English usually occurs once they interact with their pals rather than interact with other people. Hallyu International fans, like Koreans, also use English words that carry a different meaning from their original one. For example, the word "visual" is an adjective in English. However, International fans of K-pop use it as a noun to refer to the most handsome or beautiful member in the group as "the visual of the group".

\section{Hallyu Language and Corpus Planning}

Corpus Planning as an aspect of Language Planning (hereafter LP) at the community level (also known as the micro level) notably takes place on Hallyu International fans' language. The American linguist Joshua Fishman (1987) defined LP as "the authoritative allocation of resources to the attainment of language status and corpus goals, whether in connection with new functions that are aspired to or in connection with old functions that need to be discharged more adequately" (p. 409). In other words, LP is the elaborated policies and programs that are set for a language change either to gain official status as Status Planning, to go through Modernization, Graphization, or Standardization as Corpus Planning or through an educational attempt of a government system to influence a language status, distribution, or literacy as Acquisition Planning. Its implementation starts ranging from governments, to language academies, to individuals.

Regarding that Hallyu International fans' language is neither a language variety to go through Status Planning nor its speakers demand Standardization for it, only Graphization and Modernization as two types of Corpus Planning apply to it. According to Haugen (1983), Corpus Planning is internal to language, i.e., it mainly involves its linguistic aspects. The latter are defined by Baldauf (1989) as: "(1) orthographic innovation, including design, harmonization, change of script, and spelling reform; (2) pronunciation; (3) changes in language structure; (4) vocabulary expansion; (5) simplification of registers; (6) style; and (7) the preparation of language material" (p. 11). Graphization signifies the elaboration, adaptation, and selection of scripts and orthographic forms for a language. Modernization refers to a language's lexicon expansion that enables it to discuss modern semantic domains (K-pop and K-drama in this thesis) and meet functions through increasing terminology resources.

\section{Method and Procedures}

This part tackles the research questions that are addressed through this study, purpose and significance of this study, the selected sample, and the method how data is collected and analyzed.

\section{Statement of the Problem}

Hallyu International fans share common communicative language characteristics through conversation. People who are not fans of K-pop and K-drama may not have a linguistic perception of this community's language, which switches between the mother tongue (Algerian Arabic in the case study) and an "Alien" language. However, this impact fails to take into account the linguistic reason behind the inevitability of this kind of conversational language change and the mutuality of its characteristics among International fans. This problem is addressed through answering the following research questions:

(1) What are the distinctive characteristics of the language of Korean pop music and drama?

(2) How does Hallyu influence appear through International fans' speech?

(3) How does Hallyu influence make International fans express themselves?

(4) How does Hallyu influence take place on Algerian fans' language? 
(5) What are other aspects of Algerian fans' attitude towards Hallyu?

(6) How does Corpus Planning apply to Algerian fans' language?

(7) What are the developing phases through which Hallyu influence shows increasing seriousness on Algerian fans' language?

\section{Purpose of the Study}

This study aims at scrutinizing a new kind of language use at a speech community level within foreign fandoms of the Korean Wave (Hallyu) globally and in the Algerian society as a case study. Moreover, this study examines how Hallyu makes International fans' linguistic behavior highly noticeable and distinctive once pals interact or create communities (mostly fan blogs) within which they use a language that only they can understand.

\section{Significance of the Study}

Previous few, if any, academic studies on Hallyu influence on the language of International fans in the Arab world were conducted. This issue creates a research gap within the domain of Conversation Analysis. Therefore, the significance of this study is that it is one of the first studies of this kind to shed light on how this kind of entertainment can stand as a salient factor of conversational language change, especially language of foreign fans of a particular entertainment product. Thus, it may increase the scale of language domains of variance study considering the importance of fandom language as a point of variance, which gives birth to a new linguistic guise of conversation. This study may be a grounding one to further research that may necessarily tackle not only Hallyu International fans' language but also different kinds of fandom languages.

\section{Characteristics of the Korean Wave}

Korean entertainment products (music, drama, TV shows, and technology) have raised a huge continuous storm around the world in the 1990s starting from China and Japan to the United States, Latin America, the Middle East, and some parts of Europe. This unstoppable "cultural" storm is referred to as the "Korean Wave". The latter is also called "Hallyu" (한류 in Korean), a term was coined by China's Beijing Youth Daily in 1999 to describe the Korean pop effect on China (RAVINA, 2009). "According to Ko (2005), we need a cultural theory not bound by national limits in order to understand the Korean Wave phenomenon" (as quoted in Lee, 2011, p. 86). Hallyu was born as a way out of the economic crisis South Korea got into in 1997. In an attempt to gain universal popularity, Korean music and drama started to adopt concepts and standards that appeal to a global audience, especially to the U.S. TV shows were not aired at Arab Muslim prayer times for the sake of gaining Arab audiences in order to watch them in their free time. Former president Kim Dae Jung insisted on breaking stereotypes of treating external investors like invaders for a better future for the country. Eventually, if South Korea was not trapped between a serious economic crisis and the absence of natural resources to help to overcome it, there probably would not have been a Korean Wave (Hallyu).

\section{K-pop}

As defined by Kpop for Beginners (2017), K-pop is an abbreviation of Korean pop or Korean popular music which refers to a musical genre consisting of electronic, hip hop, pop, rock, and R\&B music originating in South Korea. Korean pop comes in a magic form of mixed Western-Korean style with unique vibes that gather impressive voice quality, dramatic videos with stunning graphics and inspiring lyrics all performed by aesthetic-like artists. These features are what motivates non-Korean audiences to enjoy this music genre even 
with the language barrier; they enjoy it even if they do not understand the lyrics. They wait for English or Arabic translation to come out or start learning Korean. "K-Pop utilizes the English language in varied ways as well, whether to insert youthful rebellion or challenge tradition, while at the same time maintaining traditional values in the Korean lyrics" (Leung, 2012, p. 84). K-pop groups consist of large numbers for choreography goals; they perform highly sophisticated dances that are split-second synched with their music. Hong (2014) stated that K-pop is overtaking J-pop (Japanese pop) in the west because Korean culture is naturally puritanical and conservative and that is a good thing for global audiences. In general, Hallyu not only delivers entertainment products, but also delivers a lifestyle (cultural habits, tastes, mode of living, and a new language). It is available in a "package deal" in worldwide markets; a fact that consumers may or may not realize.

\section{K-drama}

Korean dramas are mini-series with a standard of 16-20 episodes. They are mainly divided into "Romance/Comedy, Melodrama, Makjang (Extreme Soap Opera Melodrama), and Sageuk (historical drama)/Fusion Sageuk (historical drama containing modern scenes/elements or fantasy). There are also medical and crime dramas in addition to work-place dramas, Misaeng. In South Korea, the word "drama" is equivalent to the word "series" in general. Therefore, "drama" refers to any genre of series.

$\mathrm{K}$-drama features are incomparably numerous. The most remarkable feature is the fact that they deliver the norms of Korean culture in daily life. Korean TV is clean, as compared to American movies, and street swearing is rarely uttered. Watching a K-drama gives fresh vibes with new language, new plots (that are flexible to develop, based on viewers' reactions), new culture, and new life issues of people with a different ideology.

South Korean dramas typically deal with family issues, love, and filial piety in an age of changing technology, and often reinforce traditional values of Confucianism as "an ethical system that is taught in Chinese schools as a religion that is based on affection towards parents, family, and friends". (Ryoo, 2007, p. 140)

\section{Literature Review}

Linguists and researchers continuously publish studies and academic writings about varieties of discourse and daily talk based on ethnicity, identity, gender, and other domains of research. However, only few of them examined conversational language use of fandom communities, especially, that of foreign fandoms oriented towards a sort of entertainment. In this historical review, studies and articles concerned with this unique linguistic phenomenon will be set under lights as items that provided the exposure of this important issue. Priority of reviewing is for works that have dealt with the effect of Hallyu and then general previous works on fandom language are tackled.

Chan and Seo (2011) claimed:

Why do university students in Singapore decide to learn the Korean language? There is anecdotal evidence that Hallyu or the Korean Wave may have promoted a keen interest in Korean pop culture and media, and encouraged many to learn Korean in Singapore. (Chan \& Seo, 2011, p. 1)

Estavillo (2012) highlighted that the Korean entertainment is not only popular in Philippine but it is a world-encompassing phenomenon. "Hallyu" or the "Korean Wave" is matchless. It is being enormously consumed in all parts of the world.

Otmazgin and Lyan (2013) stated: 
Many K-pop fans tend to tap into other Hallyu-associated products and fields, especially TV dramas. About two-thirds of the fans we interviewed (eleven out of eighteen), both Israeli and Palestinian, told us that they started to listen to K-pop after becoming fascinated with Korean TV dramas and listening to the drama's background songs. (Otmazgin \& Lyan, 2013, p. 75)

The last third is that a part of K-pop fans who play a big role in being active on Internet forums are devoted to Korean culture products, in Hebrew (for Israeli Jews) and Arabic (for Palestinians), and sometimes in English and Korean as well. Via network fandom activities, they share numerous pieces of information, pictures, music videos, and gossips about K-pop. They also make friendships with other fans by means of creating online communities.

According to the sociologist Al-Nuri, after the invasion of Korean technology, it is TV screen time to take over the universe with loads of dramas that caught the youth's attention in the Arabic society. She also claimed that young people are not just clearly having haircuts similar to those of main characters in these dramas in the Iraqi society but also tend to learn some Korean words particularly how they write their names in Korean (Abdullah, 2013).

Trish (2014) stated in his website article that International fans approve the Korean culture through watching dramas and variety and reality shows that represent lifestyle in Korea. When they get familiar to this lifestyle, they come to "grasp towards the things Koreans normally do. In fact, International K-pop fans do not only see to it that they know a particular practice. Most of them do also live up to it". These fans, without realizing, will find themselves becoming a "Koreaboo". The term "Koreaboo" is derived from the term "weeaboo", which refers to a non-native person who has a remarkable obsession towards the Japanese culture. Fans in their "Koreaboo Stage" gradually take in the different practices of Korea and let themselves be engulfed by them. They will then start adding Korean words in their sentences, eat Korean food often, imitate Korea's sense in fashion, watch Korean dramas, and even want to live in Korea just so they could be closer to their idols. International fans use Korean words in their daily talk because of the uniqueness of these words, which means they are only used in the Korean society.

Accepting K-pop as one's music genre encourages International fans to adopt the culture via learning Korean and then International fans become able to distinguish it from other "chingchong" languages of Northeast Asia. This makes International K-pop fans cross Korea and another country's language barriers in order to get an idea of what a particular song is saying.

Trish (2014) also stated that most fans, especially those who are new to the K-pop world, are usually excited about not understanding the songs. It gives a hint of mystery to the listener to guess the song's message and it makes the listener just solely feel the song and the emotions of the singer. Once that person looks up the English (or Arabic) translation of it, it often makes the listener feel the song even more. That is why these fans try their best to cope with the complexity of the Korean language, whose accent doubles its complexity. Along the way of being a K-pop fan, it is very inevitable not to pick up words out of the Korean vocabulary.

Other similar researches about other attention-seeking entertainments are those about Anime and Harry Potter that show how their fans adopt a different language use once they become obsessed with them. Anime is a Japanese abbreviated term for hand-drawn or computer animation. This term refers to all animation in Japan while it refers only to Japanese animation series or films outside Japan. Harry Potter is a series of fantasy novels written by British author J. K. Rowling. These novels (that are now TV series) chronicle the daily life of a wizard called Harry Potter and his friends Hermione Granger and Ron Weasley who are all students in 
Hogwarts School of Witchcraft and Wizardry. Both Japanese Anime and Harry Potter series have their own language that their fans adopt and communicate with.

Fukunaga (2006), in his study comparing between JFL (Japanese as a Foreign Language) students who watch Anime and those who do not, highlighted that "Anime students" seem to be open to Japanese language and culture and its subcultures before starting classes. "In Japanese class, anime students put their prior knowledge to use while they gain new knowledge of vocabulary, grammar, writing systems, and culture" (Fukunaga, 2006, p. 215). Students who are used to listening to Japanese obtain accurate pronunciation. "Young adults in the United States learning Japanese motivated by anime and its subcultures and Japanese audiences of a South Korean TV drama studying Korean indicate the beginning of an alternative version of globalization and multiculturalism" (Fukunaga, 2006, p. 221).

Anime fans seem to be influenced not only in their tastes but also in how they perceive language. Terms in Anime become a mutual communicative base for International fans. "Like any community bound together by common interests, we adopt jargon words that only really have meaning for us. And since we're into a foreign language media, a lot of our specialised vocabulary consists of Japanese loan words" (Frog-kun, 2013, p. 2). Speaking about Anime in English makes fans use words like kawaii (cute), shonen (first year), shojo (virgin), yaoi (boys love), and otaku (geek), even if they do not speak Japanese.

Smith (2015) assumed that each person has their own characteristic and semantically different discourse for which they decide what knowledge others should have to participate in. For instance, a word that is so necessary to know in order to talk about Harry Potter is a "Muggle". The latter refers to a person who is not from a magic-family and may not even know that magic exists. "In this case, the discourse I will be talking about is a Harry Potter fan. This discourse has its own language, beliefs, practices, etc." (Smith, 2015, p. 4).

\section{Methodology}

\section{Sample and Data Collection}

The participants selected to accomplish this study are 139 Hallyu fans in the Algerian society. These participants are members in the Facebook group "DZ KPOPERS MENTAL HOSPITAL". This group includes more than 20.000 fans from all over Algeria, which offers an advantage for undertaking a national study rather than a regional one. The questionnaire was posted on the Facebook group and 160 members responded to it. However, after reviewing answers, 21 non-valid answers were eliminated in order to only work with reliable data. Algeria is located in the North-West of Africa and its population has the ability to learn and speak many languages fluently and eloquently along with Algerian Arabic as their mother tongue. "Algeria was a place of invasion and a crossroad of civilizations that made the linguistic plurality reign among its speakers since antiquity" (Chami, 2009, p. 385). Participants who understand English work best with this study because Hallyu is a Korean-English culture with a "double-language" impact that appears more notably on people who understand English and practice it in conversations. The sample includes fans who are keeping up with K-pop and K-drama for more than one year in order to detect traits that are more influential. Their age starts from 18; adult fans are fully-grown and having their language use changed shows that this influence is serious since they know well what conversational language change means and that it is a change for a linguistic purpose and not just for fun as younger people may think. 


\section{Method and Data Analysis}

Data analysis was accomplished by means of questionnaire that is a fundamental instrument which helps to reach the objective of this study using both open-ended and closed-ended questions. The researcher designed the questionnaire based on her daily observation on pals' interactions in Algeria and after analyzing International fans' attitude towards the Korean Wave via Social Networking Sites (SNS). Twenty-nine questions were designed on Google Docs, which processed and calculated data for results. Two associate doctors and one assistant doctor at English Department, at Yarmouk University, validated this questionnaire.

\section{Findings and Discussion of the Study}

This analysis shows how the Korean Wave influences Algerian fans' conversational language and their conception of the world. The practical study presented in this chapter is undertaken in an attempt to answer the following research questions:

(1) How does Hallyu influence take place on Algerian fans' language?

(2) What are other aspects of Algerian fans' attitude towards Hallyu?

(3) How does Corpus Planning apply to Algerian fans' language?

(4) What are the developing phases through which Hallyu influence shows increasing seriousness on Algerian fans' language?

\section{Data Analysis}

(1) Since when do you follow K-pop and K-drama? (Write the year exactly)

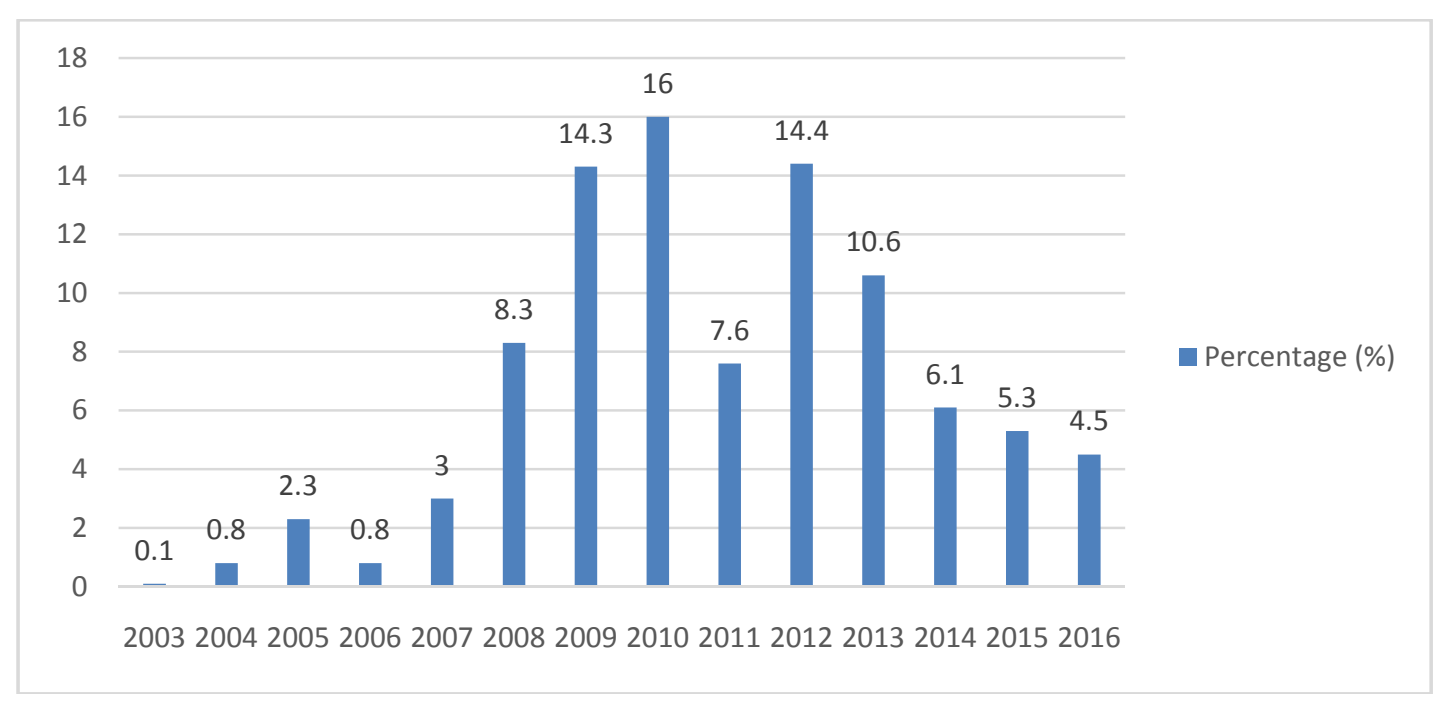

Figure 1. The year when participants started following K-pop and K-drama.

Participants answered with numerous years when they started to watch K-pop and K-drama and followed their news. Answers that did not mention the year exactly were eliminated. One percent started in $2003,0.8 \%$ in $2004,2.3 \%$ in $2005,0.8 \%$ in $2006,3 \%$ in $2007,8.3 \%$ in $2008,14.3$ in $2009,16 \%$ in $2010,7.6 \%$ in 2011 , $14.4 \%$ in $2012,10.6 \%$ in 2013, 6.1\% in 2014, 5.3\% in 2015, and 4.5\% started in 2016 (see Figure 1).

(2) Why do you like K-pop and K-drama? 


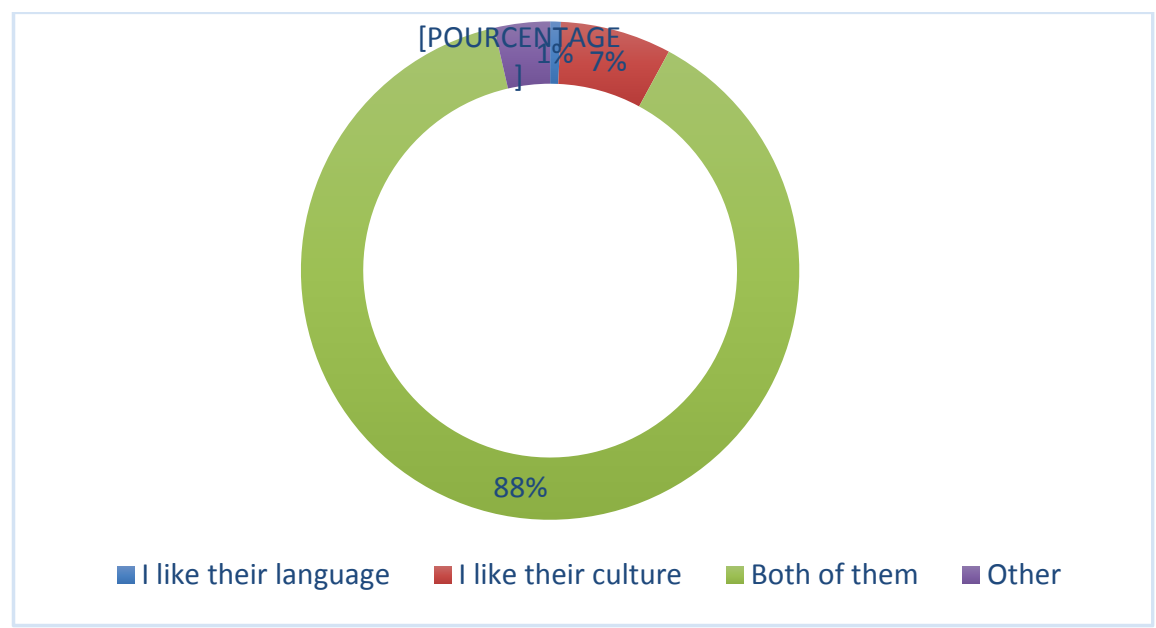

Figure 2. The reason why participants like K-pop and K-drama.

Results from the figure above show that $1 \%$ of participants like the Korean language, $7 \%$ like the Korean culture, $88 \%$ like both the Korean language and culture, and $4 \%$ of them like K-pop and K-drama for other reasons (see Figure 2).

(3) Do you prefer K-pop and K-drama over other foreign entertainment products?

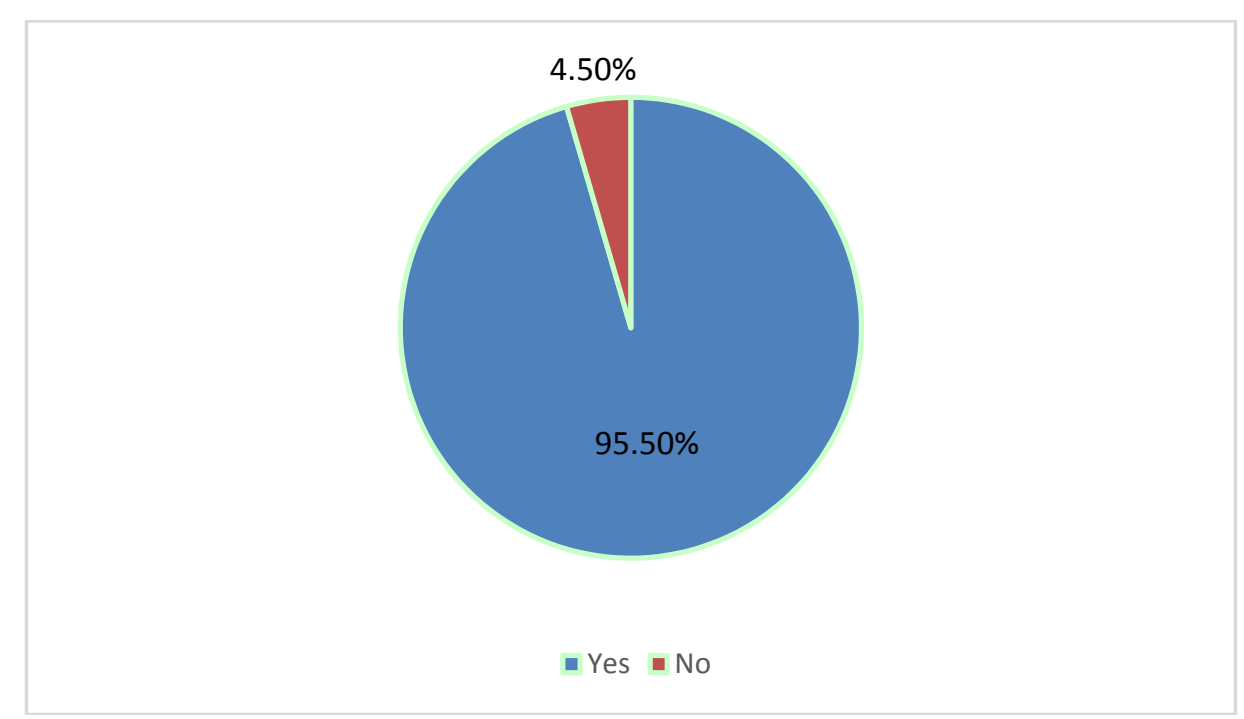

Figure 3. Participants preference of K-pop and K-drama over other foreign entertainment products.

Results show that $95.5 \%$ of participants prefer K-pop and K-drama over other foreign entertainment products and only $4.5 \%$ of them indicate that these two are not their ultimate preference (see Figure 3 ).

(4) Do you follow Korean music and drama more than Algerian ones? 


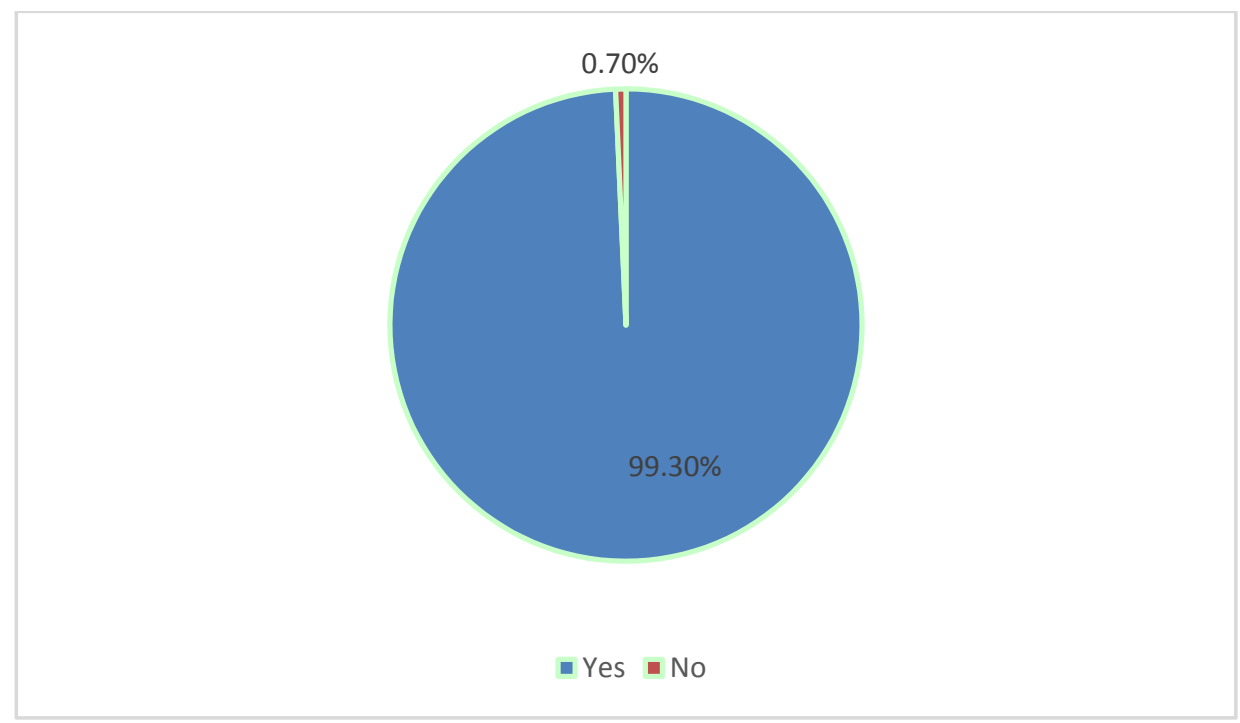

Figure 4. Participants preference of K-pop and K-drama over Algerian entertainment products.

The percentage of participants who prefer Hallyu entertainment products over Algerian ones is huge with $99.3 \%$. On the other hand, only $0.7 \%$ of them prefer Algerian music and drama (see Figure 4).

(5) Do K-pop and K-drama influence you?

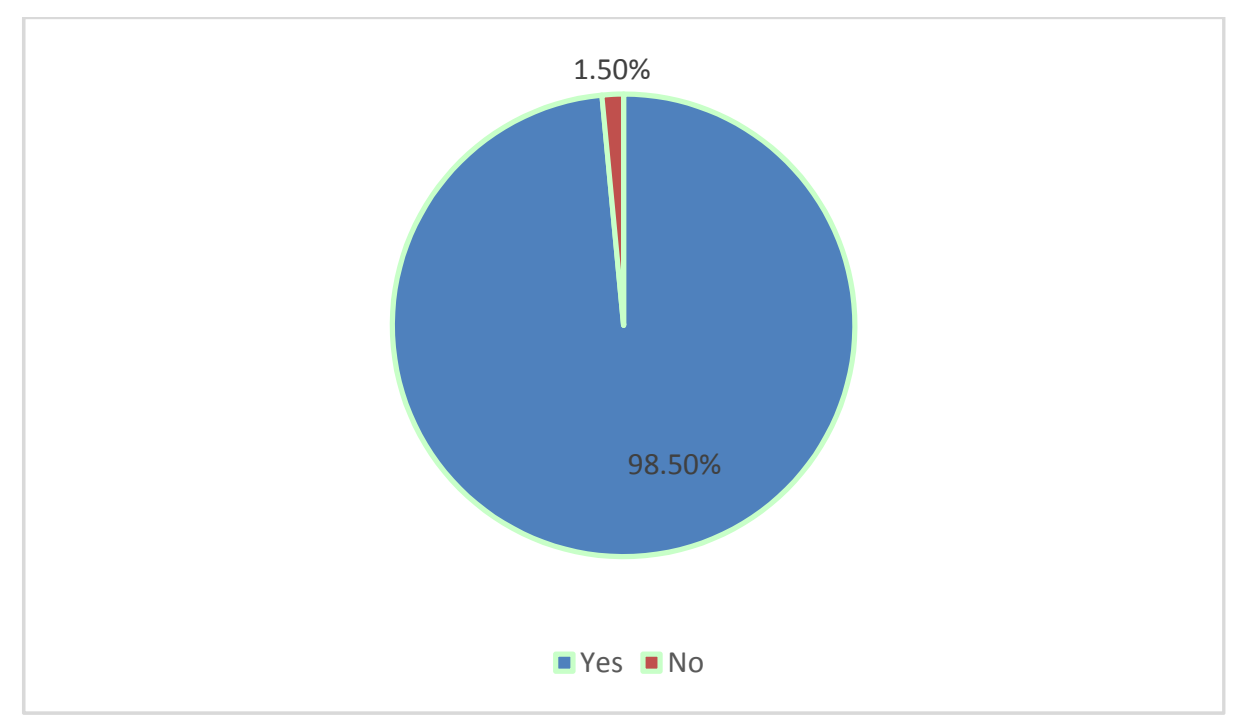

Figure 5. The percentage of Hallyu influence on participants.

The influence is common among participants with a high percentage of $98.5 \%$. The value of participants who disagreed with Hallyu influence on them is a low one of $1.50 \%$ (see Figure 5).

(6) If yes, in terms of what? 


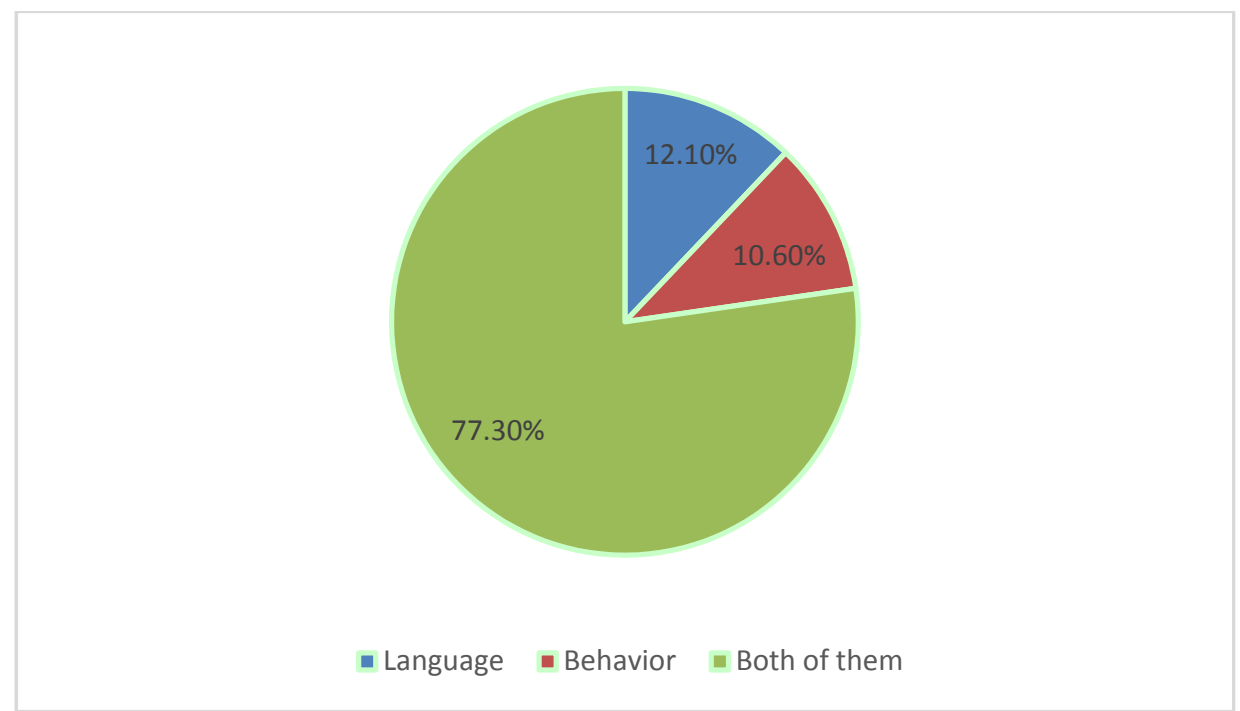

Figure 6. The aspect of Hallyu influence on participants.

Hallyu's influence on participants is more noticeable in terms of language with $12.10 \%$ rather than behavior with $10.60 \%$. However, participants who reached the highest percentage of $77.3 \%$ are those who are influenced in terms of both language and behavior (see Figure 6).

(7) Do you want to learn Korean?

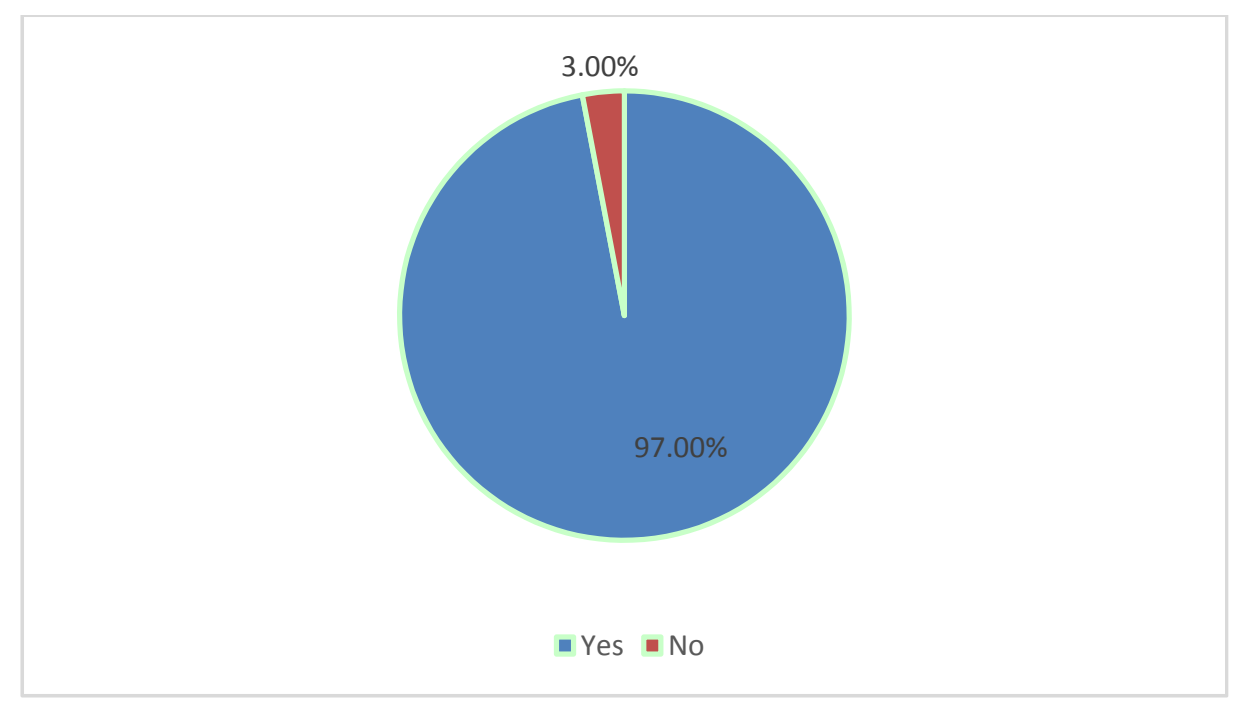

Figure 7. Percentage of Participants' Desire to Learn Korean.

Results reveal that $97 \%$ of participants want to learn Korean while only $3 \%$ do not have a desire to do so (see Figure 7).

(8) If yes, why? Because: 


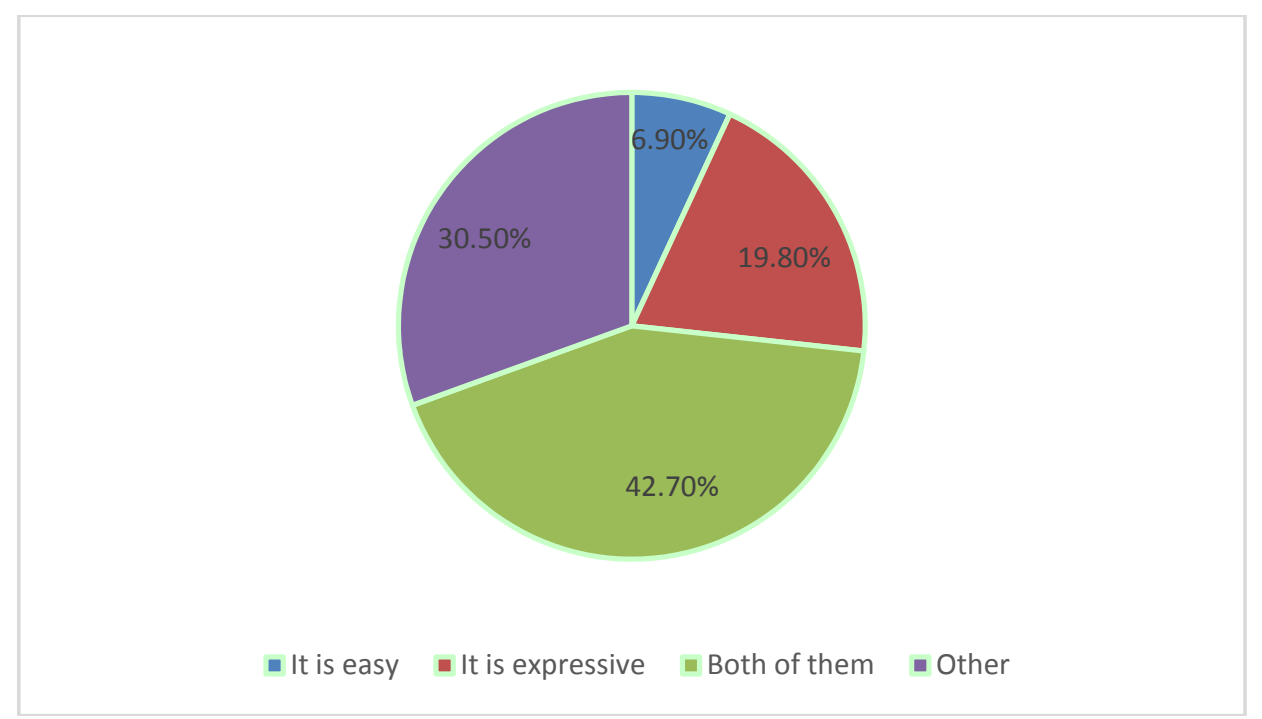

Figure 8 . The reason why participants want to learn Korean

The graph above shows that $6.9 \%$ of participants want to learn Korean because they find it easy to learn. $19.8 \%$ of them find it expressive and $42.7 \%$, as the majority of them, find it both easy and expressive. Thirty and half percent of them want to learn Korean for other reasons (see Figure 8).

(9) Do you use some Korean words and expressions (like "aiish") in your discourse?

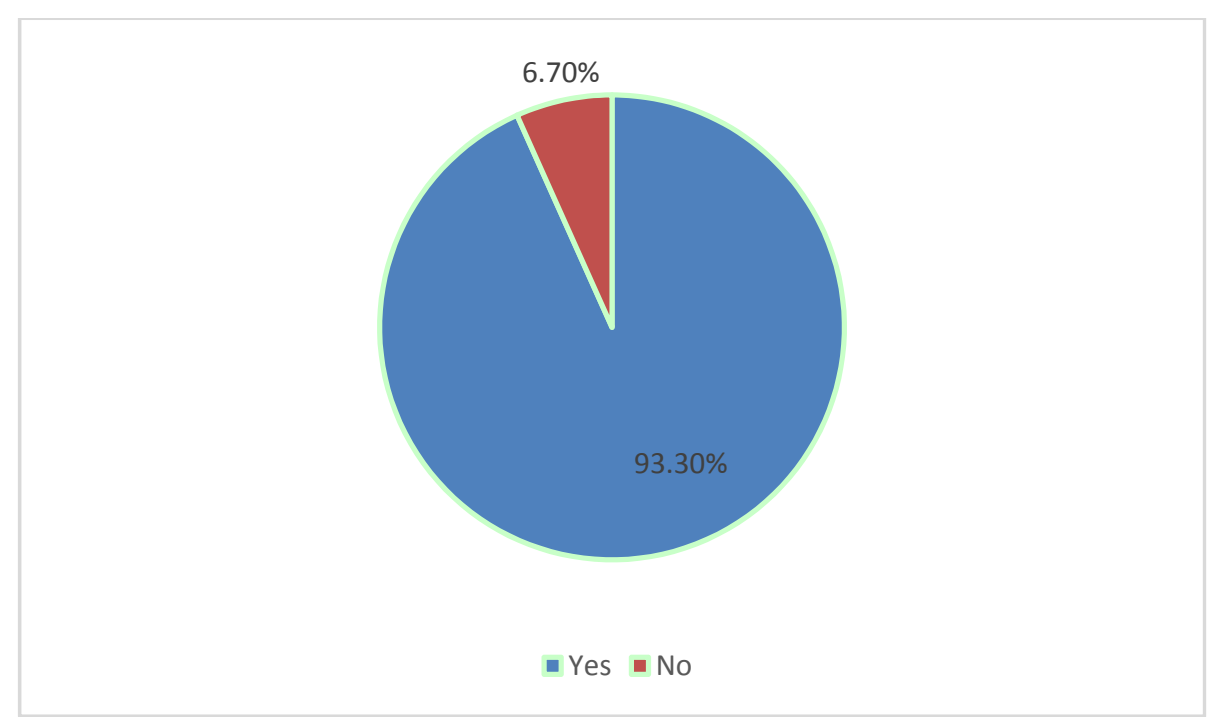

Figure 9. The value of participants' use of Korean words in their discourse.

A value of $93.3 \%$ of participants uses Korean words and expressions in their discourse while $6.7 \%$ of them disagreed with the effectiveness of this aspect of Hallyu language influence (see Figure 9).

(10) If yes, give examples of these Korean words or expressions (With English translation).

Aegyo: Cute gestures with kind of baby talk that show innocence

Ahjumma: A honorific nickname for a woman who is at a mother age

Ahjusshi: A honorific nickname for a man who is at a father age

Aigoo: An utterance to show annoyance or frustration 
Aiish: A meaningless utterance to show disappointment or bad reaction to something Ajaaja: When a person wants to support themselves or others, they say "ajaaja!"

Appa: Means dad

Andwae: Informal way of saying "it won't happen!" or "impossible!"

Ani/Anyo: Informal way of saying "no" or "not at all" (as a reply to thanks)

Annyeong: Informal "hi"

Babo: Means "stupid" or "goofy"

Bogoshipeo: Informal "I miss you" (with no subject)

Cheongmal: "For real"

Chingu: Means "friend"

Daebak: A word that expresses impression with someone/something or reaction to a great victory

Dang-yeonhaji: Informal "of course"

Dongseang: Younger brother/sister

Eodi: Informal "where"

Eonni: A girl calls her older sister/friend "eonni"

Hajima: Informal "do not"

Hal-abeoji: Means grandfather

Hul: An utterance that expresses dissatisfaction or awkwardness

Hwaiting: Korean equivalent to "fighting" that is said to show support for oneself or for others (usually comes after “ajaaja!")

Jebal: Means "please"

Jaljayo: Means "sleep well"

Jalgayo: Literally means "go well" that signifies to "good bye"

Jogeum: Means a little bit of something

Jigeum: Means "now"

Komawo: Informal "thank you" (no subject)

Kaja: Informal "let's go"

Krae: Means "right" or "yeah"

$K u l$ : Means "honey" and is used to express agreement on a deal or a suggestion

Magnae: The youngest member in a family or in a group

Miahnae: Informal "sorry"

Molla: Informal "I do not know"

Michyeosseo: Means "are you crazy?" (no subject)

Nae: In/formal "yes"

Nan: Means "me"

Omma: Means mom

Omo: Korean equivalent to OMG (Oh My God)

Oppa: If a girl calls a boy "oppa", he is either her older brother or her boyfriend or her close friend.

Ppalli: Means "quickly" or "be fast!"

Saeng-ilchugha: Informal "happy birthday"

Saranghae: Means "I love you" (no subject) 
Sasaeng: Once a fan is called "sasaeng", it means they are dangerous as they invade stars' privacy. Sasaengs are too obsessed that they are known for their ability to kidnap stars.

Satoori: Rural dialect spoken in South Korean countryside

Shirheo: In Korean, the sounds "s" and "sh" are symbolized with the same letter (入). "I do not want to" or

"I dislike this" in English equals the word "shireo" in Korean.

Tsundere: A warm-hearted person who acts cold and charismatic from outside

Wae: Informal "why?"

Yagsok: Means "promise"

Yeppuda: Means "beautiful"

(11) Do you use these Korean words and expressions with?

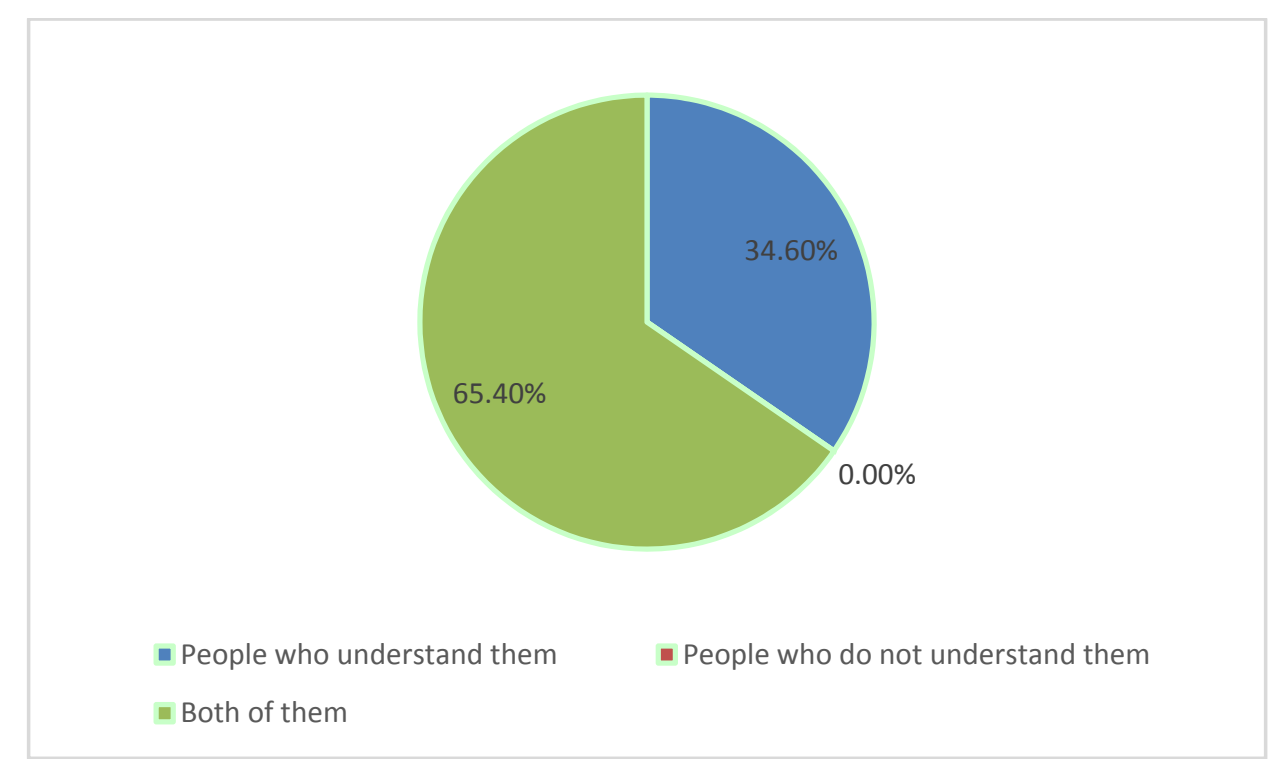

Figure 10. Interlocutors with whom participants use Korean words in their discourse.

The value of participants who use Korean words with people who understand them is $34.6 \%$ while $0 \%$ of participants use these Korean words only with people who do not understand them. A value of $65.4 \%$ of participants use Korean words with both people who understand and those who do not understand them (see Figure 10).

(12) Why do you use these Korean words or expressions with people who understand them? 


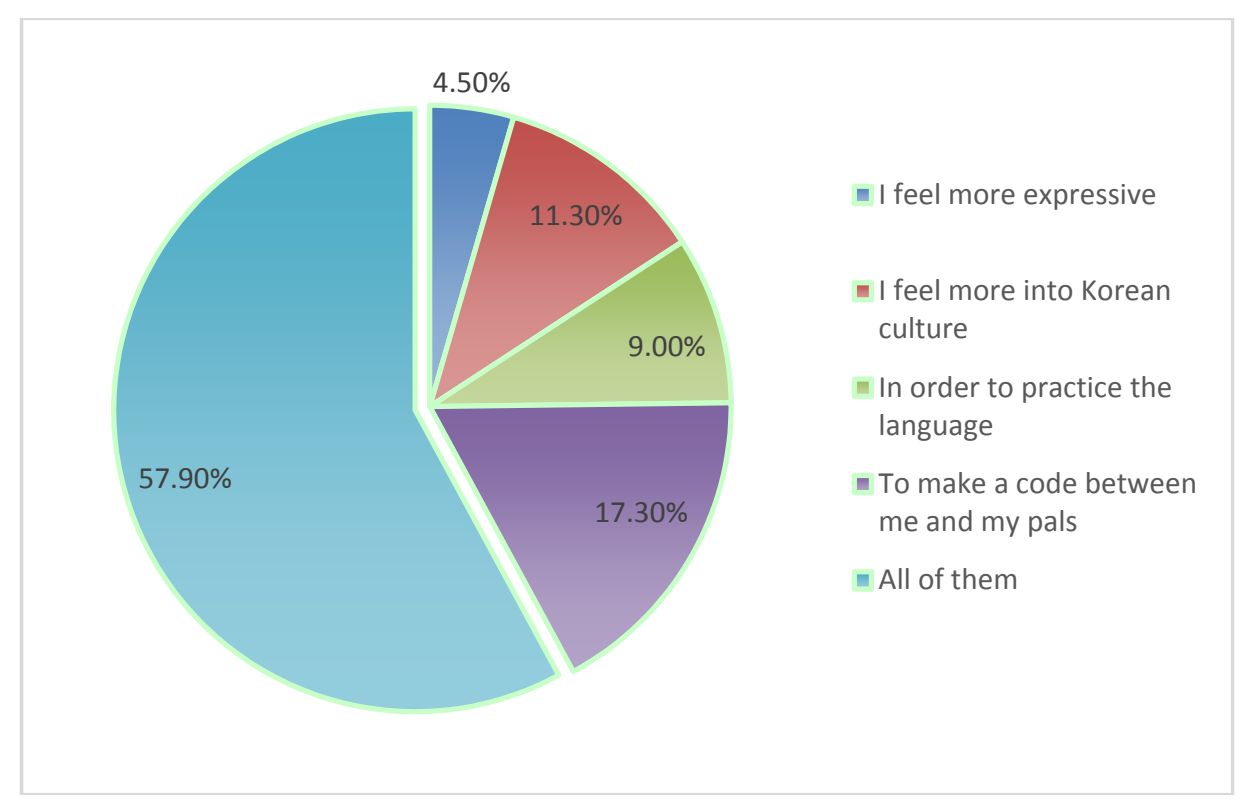

Figure 11. The reason why participants use Korean words with people who understand them.

Four and half percent of participants use Korean words with people who understand them because they feel more expressive using them, $11.3 \%$ use them because they feel more into Korean culture, $9 \%$ use them in order to practice the Korean language, and $17.3 \%$ use Korean words as a code between them and their pals. Eventually, more than half of the participants with a percentage of $57.9 \%$ use Korean words for all the previously mentioned reasons (see Figure 11).

(13) Why do you use these Korean words or expressions with people who do not understand them?

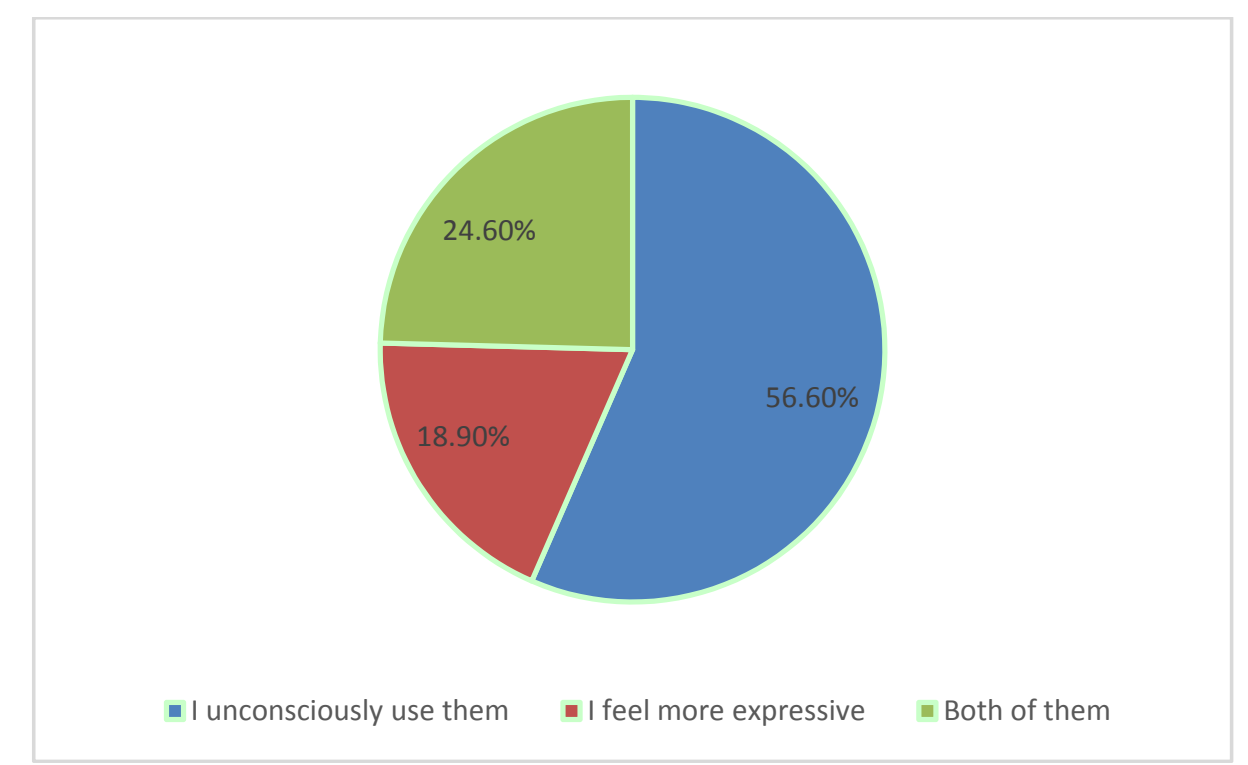

Figure 12. The reason why participants use Korean words with people who do not understand them.

The majority of participants with a percentage of $56.6 \%$ revealed that they unconsciously use Korean words in their speech with people who do not understand them, $18.9 \%$ of them feel more expressive using them, and $24.6 \%$ sometimes use them unconsciously and sometimes use them when they find them more expressive (see Figure 12). 
(14) Do you write in Korean (either Romanization or Hangul) on social media?

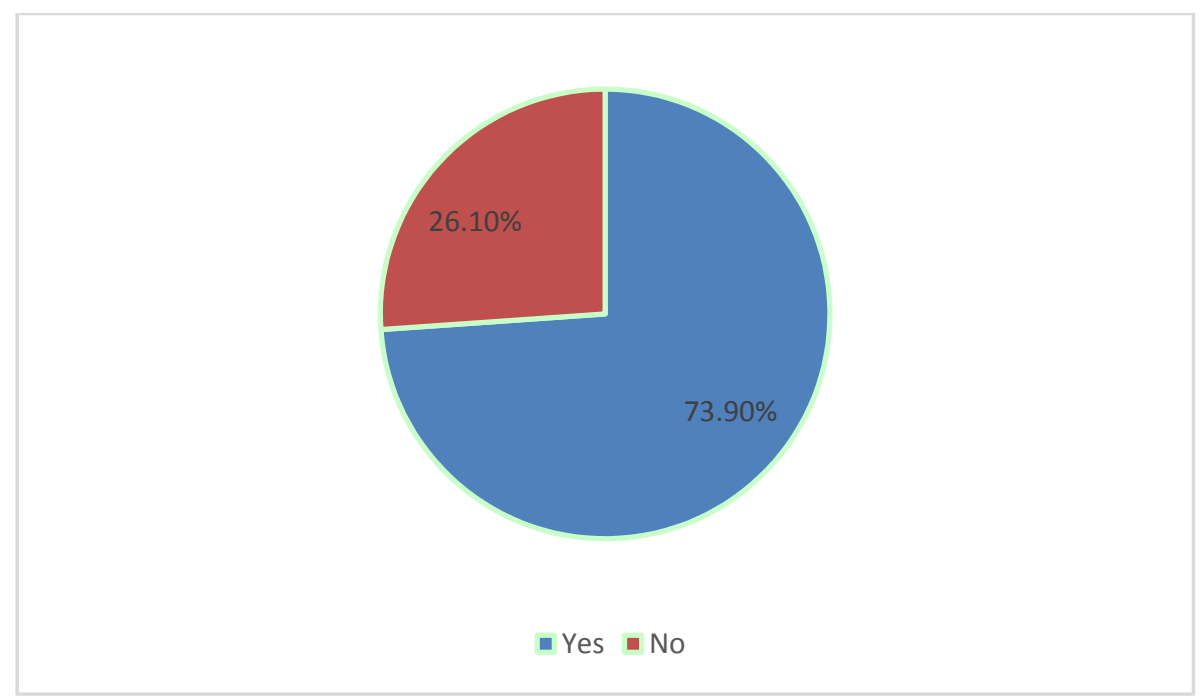

Figure 13. The Percentage of Participants' Posts in Korean on Social Media.

A value of $73.9 \%$ of participants agreed that they share posts on social media in Korean and $26.1 \%$ of them disagreed with sharing their posts in Korean (see Figure 13).

(15) Do you send SMSs in Korean to your pals?

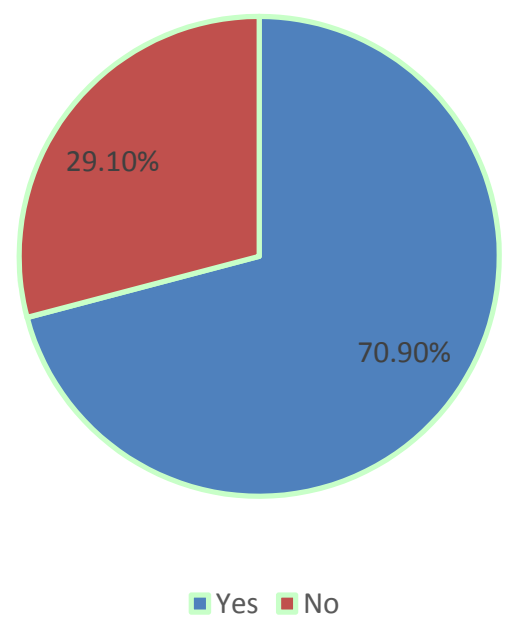

Figure 14. The value of participants who send SMSs in Korean to their pals.

The figure above shows that $70.9 \%$ of participants send SMSs in Korean to their pals while only $29.1 \%$ of them do not do so (see Figure 14).

(16) If yes, how often? 


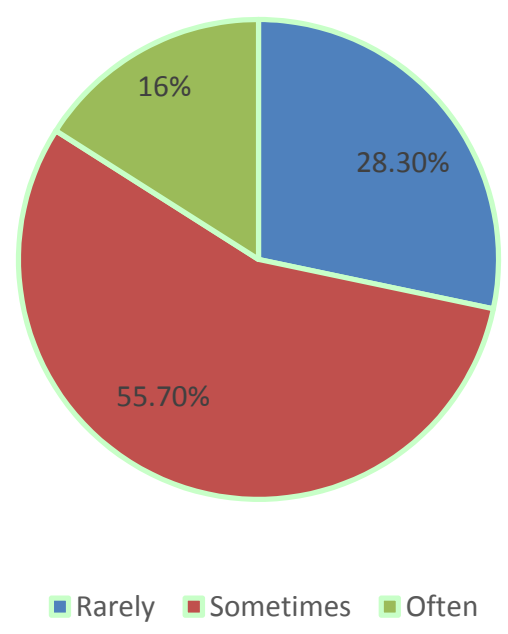

Figure 15. Frequency of participants sending SMSs in Korean to their pals.

A value of $28.3 \%$ of participants rarely, $55.7 \%$ of them sometimes, and $16 \%$ of them often sends SMSs in Korean to their pals (see Figure 15).

(17) Do your pals reply to your SMSs in Korean, too?

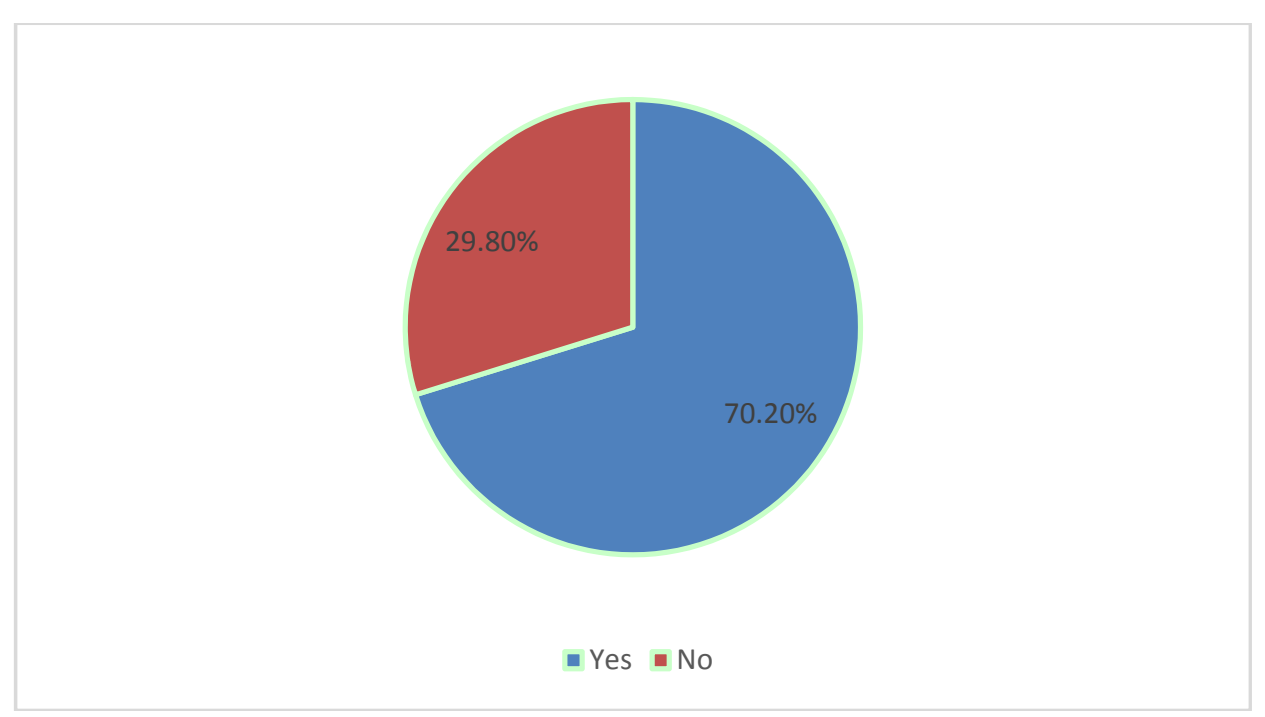

Figure 16. The value of participants receiving replies to their SMSs in Korean.

The percentage of participants who receive replies in Korean from their pals is $70.2 \%$ and $29.8 \%$ of them do not (see Figure 16).

(18) If yes, how often? 


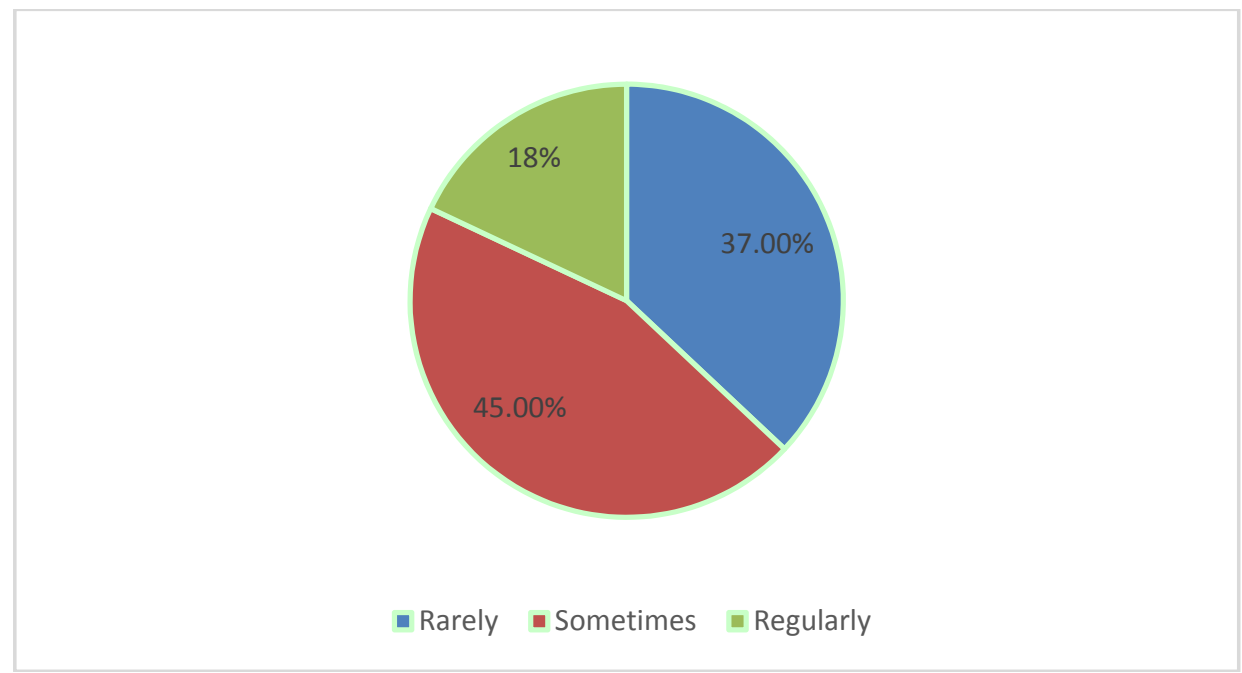

Figure 17. Frequency of participants receiving replying SMSs in Korean from their pals.

Thirty seven percentage of participants rarely, $45 \%$ of them sometimes, and $18 \%$ of them regularly receive replying SMSs in Korean from their pals (see Figure 17).

(19) Do you write random thoughts in Korean?

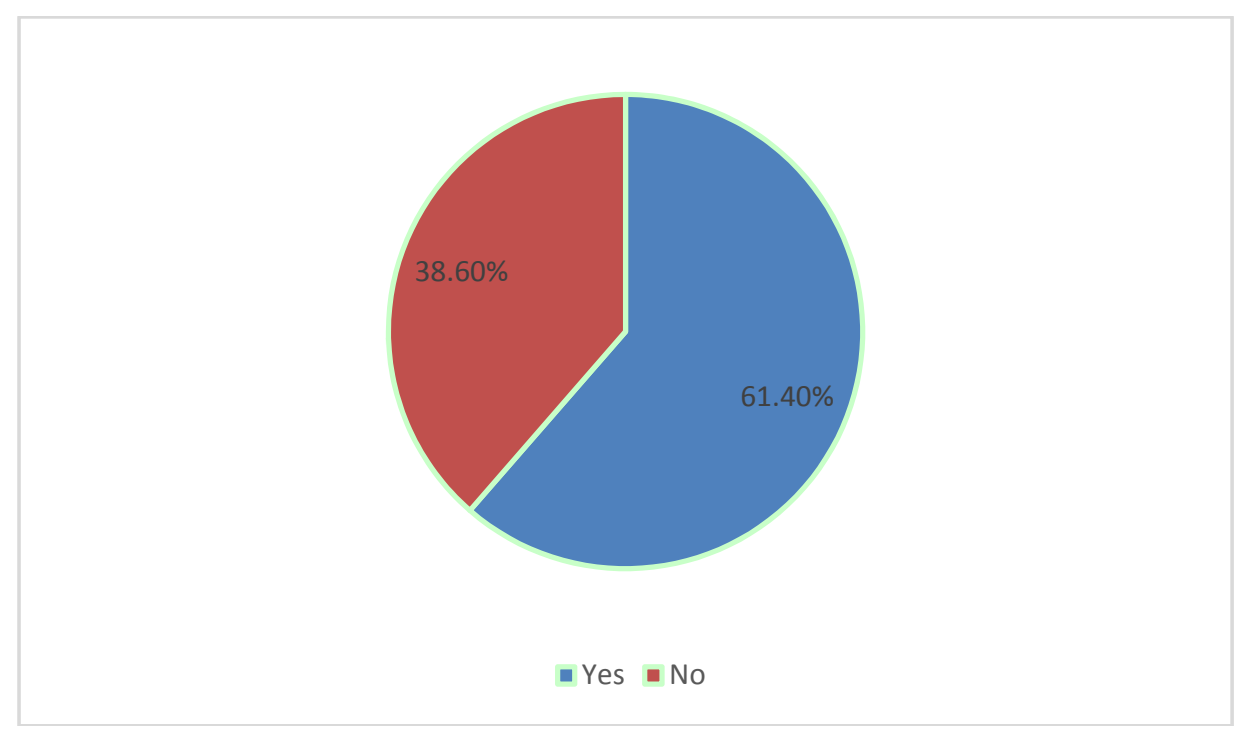

Figure 18. The percentage of participants writing random thoughts in Korean.

The percentage of participants who write random thoughts in Korean is a high one with $61.4 \%$ whereas $38.6 \%$ is the percentage of participants who do not do so (see Figure 18).

(20) If yes, how often? 


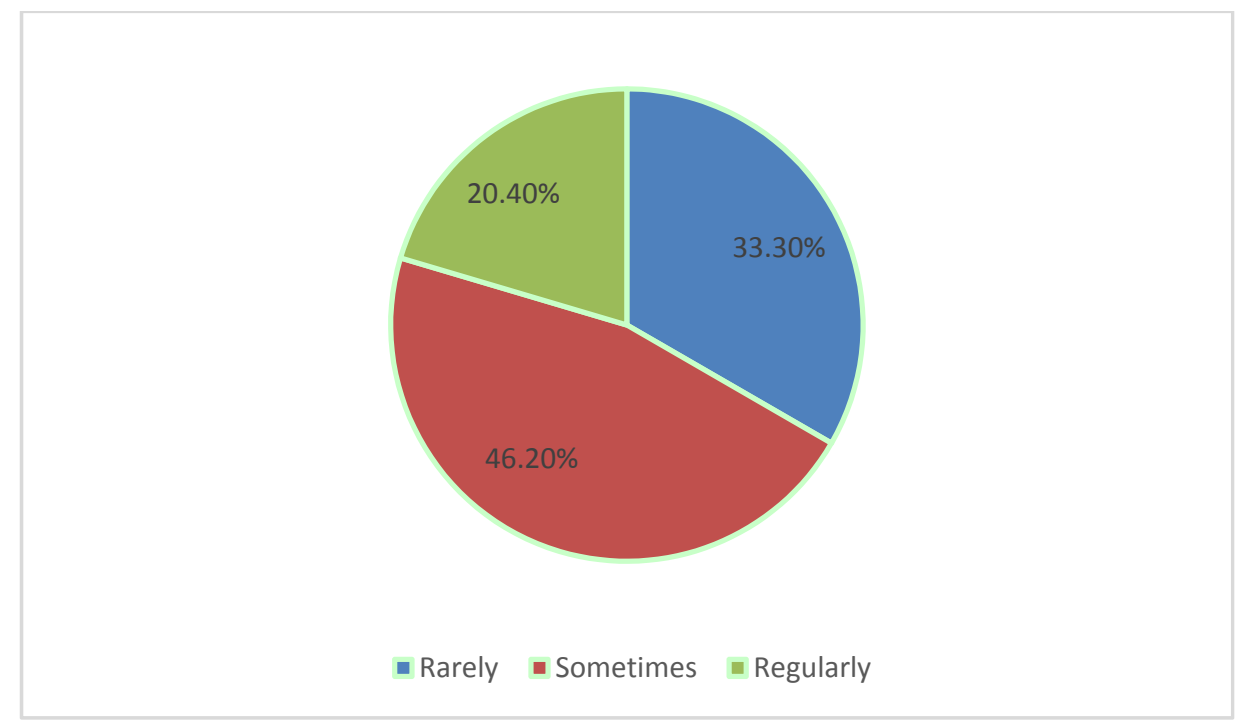

Figure 19. Frequency of participants writing random thoughts in Korean.

$33.3 \%$ of participants rarely, $46.2 \%$ of them sometimes, and $20.4 \%$ of them regularly write random thoughts in Korean (see Figure 19).

(21) Do you use translated sayings and proverbs from Korean culture into your discourse?

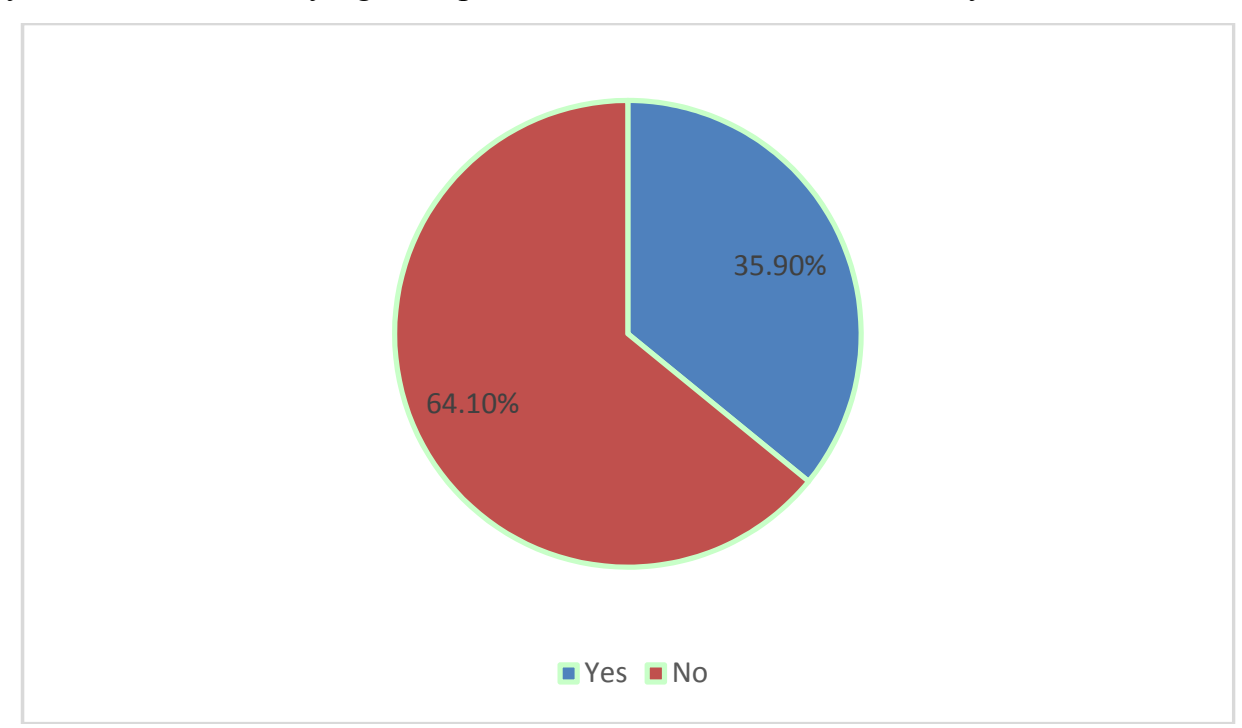

Figure 20. The value of participant's use of translated sayings and proverbs from Korean culture into their discourse.

The majority of participants with a percentage of $64.1 \%$ do not use translated sayings and proverbs from Korean into their discourse and $35.9 \%$ of them take translated Korean proverbs and sayings in order to use them in their daily discourse (see Figure 20).

(22) If yes, can you write some of these sayings and proverbs?

Participants who use some common sayings and proverbs that they learned from K-pop and K-drama in their discourse shared some examples as follows:

Even if you know the way, ask one more time.

A person has to make sure of everything even things they know well in order not to regret not asking or making sure. 
Confidence is as a paper; if it is wrinkled, it cannot be smooth again.

If people lost confidence in someone or something, it is so hard, if not impossible, to regain it.

If you do not walk today, you must run tomorrow.

Starting a work or an activity early does not require rapidity. Yet, if a person lets everything till the last minute, slowing down might not be the best decision for them.

Beauty is in the eye of the beholder.

Another way to convey this meaning is "There is beauty in everything. But not everyone can see it".

People does not need reasons, they just want someone to punish.

Koreans say this proverb for instance, when an employer in a company is punished for a huge workplace mistake instead of the biggest responsible for it, that could be the director. The latter is not punished because of his power.

When there is a will, there is a way. Rome was not built in a day.

This saying means if someone wants to have a marvelous thing (like Rome), he or she has to find the way to get it; that is hard work.

Starting is the half.

The beginning of almost everything is the hardest. However, after the beginning, the job gets easier to finish.

In the end of hard work happiness comes.

Earning something with hard work feels happier than earning it easily.

Do not throw diamonds before pigs.

Giving someone something that they do not know its value is just like throwing diamonds in front of pigs.

Be happy no matter what happens!

This saying means to have faith and believe in destiny. Faith is what makes a person happy despite all the hardships.

(23) Do you use inside jokes related to K-pop/K-drama that only you and your pals could understand?

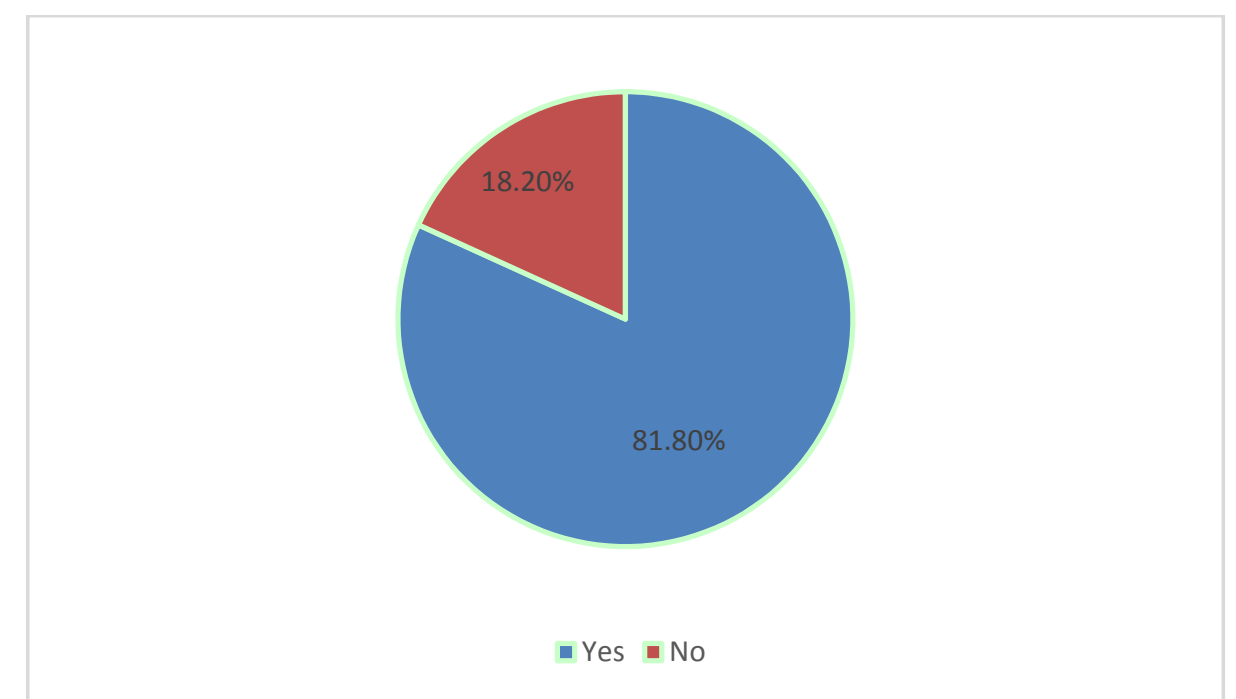

Figure 21. The value of participants' use of inside jokes related to K-pop/K-drama that only they and their pals could understand. 
The percentage of participants who use inside jokes from inside their fandom that only they and their pals could understand is $81.8 \%$ while only $18.2 \%$ of them do not use inside jokes (see Figure 21 ).

(24) If yes, give examples in sentences.

Participants gave examples as follows:

Dirty water

Fans use this expression to refer to someone's spit taken from BTS J-Hope's speech.

Strong power thank you!

BTS RM (who speaks English fluently) created this expression as an attempt to make fun while trying to translate his fellow members' thankful words for fans.

Infires man

This expression is BTS Suga's mispronunciation of the word "inspires". Fans use this expression to refer to something very inspiring that it could put someone's brain on fire.

Jungshook

This term was inspired from BTS Jungkook's shook face and is used to react to something astonishing.

Yehet

EXO Sehun uses this term when he is happy or to show satisfaction. His fans also use it to express their happiness.

You got no jams

The word "jam" in English sounds like the word "jaem" (fun) in Korean. It is taken from BTS RM's speech to refer to a boring person.

Hey! Stahb it

This expression is BTS's Jin's wrong pronunciation of "stop it" that fans use it as an inside joke.

Do You Like Messi?

This question is taken from the K-drama "Weight Lifting Fairy". Fangirls use it to show their interest in the preferences of the person they like.

Michosseo, ddorasseo, yagmogonianaega?

This question literally means "Am I crazy, freak, or do I take drugs?". It is taken from the K-drama "The Heirs" and is used when a person is asked to do something they totally reject to do or something that is shameful for them.

(25) Do you name your phone contacts in Korean? 


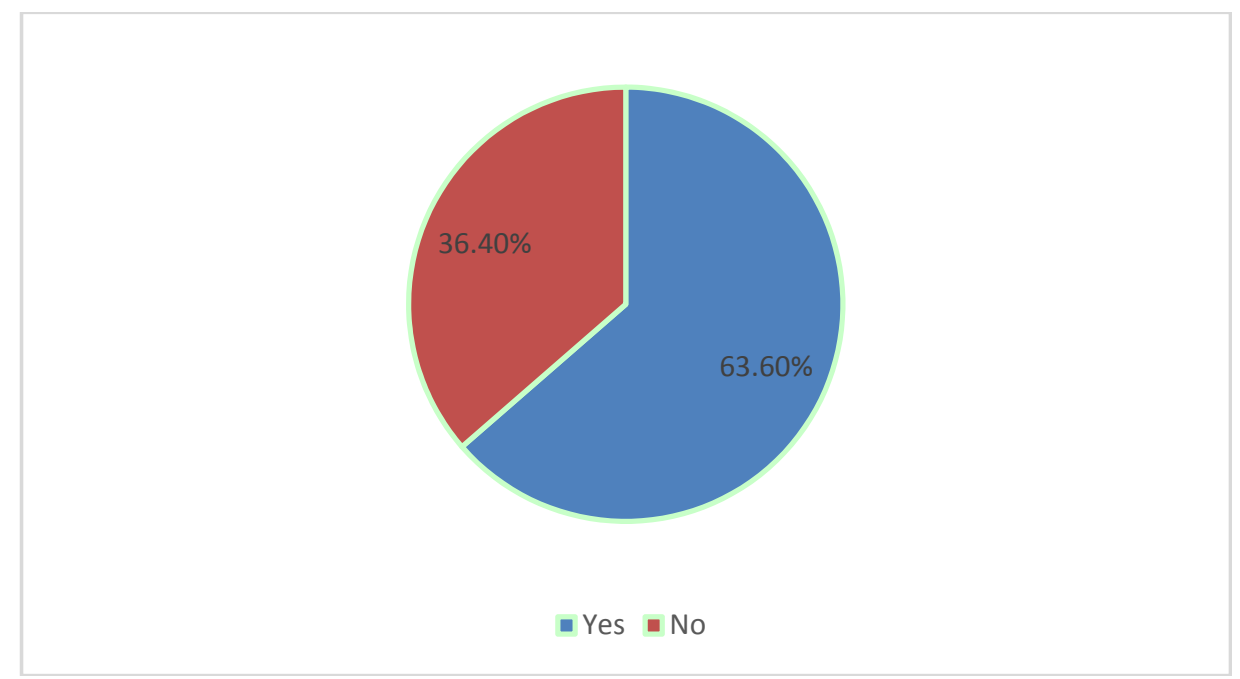

Figure 22. The value of participants naming their phone contacts in Korean.

The percentage of participants who name their phone contacts in Korean is higher with $63.6 \%$ than the percentage of participants who do not do so with $36.4 \%$ (see Figure 22).

(26) Are there any English words that you use only when talking about K-pop/K-drama?

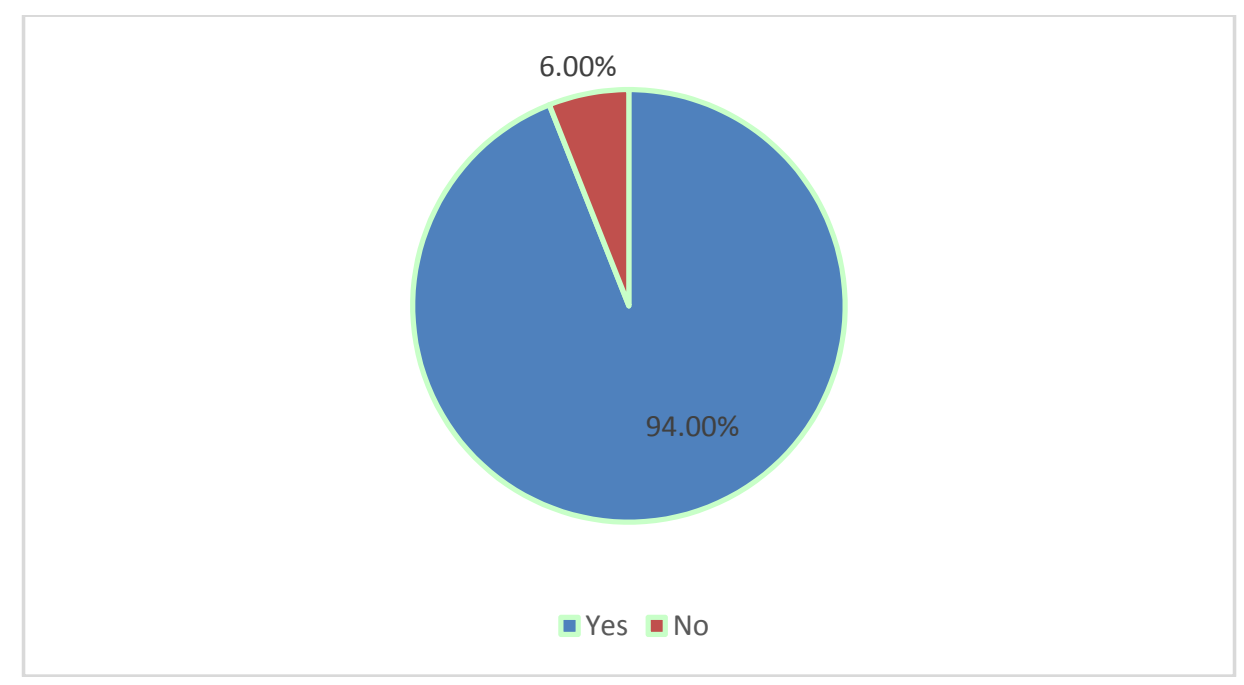

Figure 23. The value of participants' use of English words that they use only when talking about K-pop/K-drama.

Ninety four percentage of participants use English words that are only used when talking about K-pop and K-drama while only $6 \%$ of them do not have this feature in their language (see Figure 23).

(27) If yes, give examples.

All-kill: A song is an "all-kill" if it is on top of all major charts in Korea.

Bias: Most loved member in a group.

Bias wrecker: The second most-loved member in a group who may take the first place instead of the actual bias.

Comeback: A K-pop single artist's or a group's new album is called "comeback".

Comeback Show: The group's or artist's live show where they perform their new songs as their comeback.

Concept: Means the outfit or look that goes with the theme of each album. 
Drama: Participants only refer to K-dramas in general by saying "drama". They call other series.

Fan Chants: Mixed melodies with backing vocals that fans sing along with the performance they attend. Fans also shout out the band members' names with melody as a fan chant.

Fan Service: Anything stars do that is pleasant for fans, even if it is not relevant to the show.

Fanboy and Fangirl (noun and verb): A boy/girl fan who has passionate emotional attitude towards their bias. A girl fangirls or a boy fanboys by complementing their biases in a dramatic behavior.

Fandom: A love group of fans dedicated to an idol group or an actor/ess in order to support them, unconditionally.

Fansite: K-pop idols create fansites where they can make contact with their fans like Fancafe.

Flower boy: A cute and innocent boy who is metaphorically referred to as "a flower".

Golden Maknae: The Maknae of the group is the youngest among members. A Maknae is called "golden" when they are multi-talented in addition to their good looks.

Hyung Line: The oldest members in a group who are almost peers.

Leader: This position is usually given to the oldest member in a group but is occasionally given to the first member who joined the group or the member who speaks English fluently.

Main vocal: Refers to the lead vocalist in a group who sings the chorus or sings most parts of the group's song.

Main dancer: The group's lead dancer who performs the most difficult parts of the choreography in the center.

Maknae Line: The youngest members in a group who are nearly at the same age.

MAMA: Refers to M(usic)net Asian Music Awards. The latter is a huge music award show where many awards are given once in a year.

Netizen: Daily Internet users who notice everything stars do and are big critics.

OST: Original Sound Track of a drama.

OTP: Stands for "One Top Pairing" which denotes a fan's favorite ship of two male members according to how nice they are to each other.

Rookie: A newbie idol/actor or idol group.

Selca: Abbreviation for "Self-camera" meaning "selfie".

Skinship: Only Koreans and Hallyu fans use this term to refer tophysical contact.

Stan: This was inspired from Eminem's song "Stan" that talks about his passionate fan named Stanley. A "Stan" is a passionate fan and is used as a verb, too.

Trainee: Before becoming an idol, a person must be a trainee for more than four years in K-pop industry.

Trash: A fan is called a group's trash if they cannot choose their best member because they love all members. This word is not derogatory only in K-pop world.

$V$ Line: $\mathrm{V}$-shaped jaw line.

Virus: A person who spreads happiness and joy.

Visual: Also known as "the face of the group". It refers to the most handsome/beautiful member in the group.

(28) Does Korean pronunciation of English sounds influence yours? 


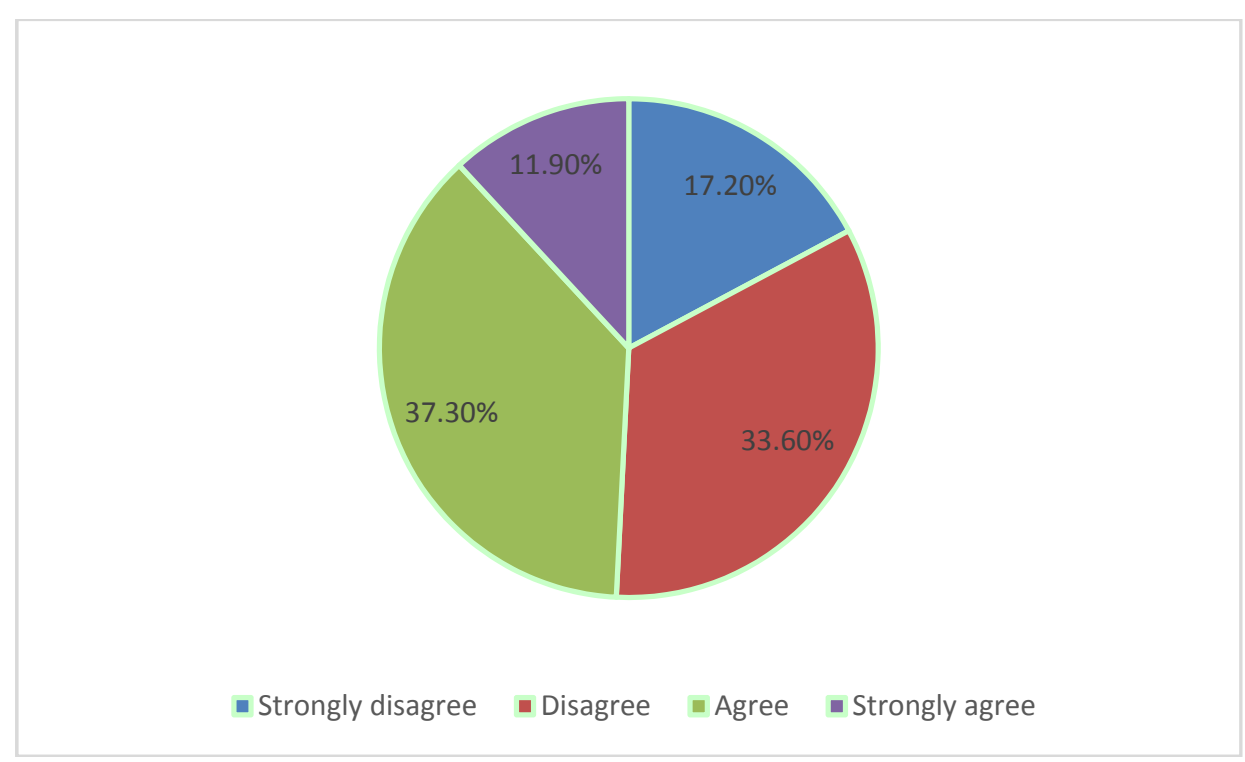

Figure 24. The percentage of Korean pronunciationof English sounds influence on participants' pronunciation.

A value of $17.2 \%$ of participants strongly disagrees, $33.6 \%$ of them disagree, $37.3 \%$ of them agree, and $11.9 \%$ of them strongly agree with the influence of Korean pronunciation of English sounds on their pronunciation (see Figure 24).

(29) If yes, give examples of English words that you pronounce with a Korean pronunciation (write changed consonants/vowels).

Words in the first colon of the table below are the most frequent ones and other examples are similar ones that participants mentioned in their answers (see Table 1). Changed sounds are: $/ \mathrm{F} /-/ \mathrm{p} /, / \mathrm{z} /-/ \mathrm{z} /, / \mathrm{r} /-/ 1 /$, $/ \mathrm{v} /-/ \mathrm{b} /, / \theta /-/ \mathrm{s} /, / \mathrm{s} /-/ \mathrm{s} /, / 1 /-/ \mathrm{r} /$ (ps. These sounds are not always changed).

Table 1

Examples of Pronunciation of Some English Sounds

\begin{tabular}{|l|l|l|}
\hline Word & Original pronunciation & Other similar examples \\
\hline Coppi & Coffee & $\begin{array}{l}\text { Pantasy (fantasy) pone (phone), pamily (family), ply (fly), tropy (trophy), pood (food), } \\
\text { pault (fault) }\end{array}$ \\
\hline Excujime & Excuse me & Pija (piza), Mujik Awadeu (Music award), jombi (zombi) \\
\hline Led Belbesh & Red Velvet & Lap (rap), lomantic (romantic) \\
\hline Lifeu & Life & $\begin{array}{l}\text { talkeu, cakeu, hearteu, wifeu, snakeu, faceu, concerteu, Englichspeakeu, kisseu, big } \\
\text { bosseu, juiceu }\end{array}$ \\
\hline Ribe & Live & Maknaerine (maknae line) \\
\hline Lobe & Love & Ober (over), bery (very), main bocal (main vocal), bampire (vampire) \\
\hline Mish you & Miss you & $\begin{array}{l}\text { Shister (sister), dresh (dress), shee you (see you), Shinderella (Cinderella), takshi } \\
\text { (taxi), Shuperman (Superman) }\end{array}$ \\
\hline Psychopasseu & Psychopath & Sree (three), shee-srough (see-through) \\
\hline
\end{tabular}

\section{Findings and Discussions}

Participants' answers show that the rise of the Korean Wave took place in 2008 when the channel Korea TV aired K-pop and K-drama with Arabic subtitles. Figure 1 shows another rise in 2012, which is the year when PSY's Gangnam Style broke global records and was the first music video to reach one billion views on YouTube. 
Most Hallyu fans in Algeria are interested in both the culture and the language of K-pop and K-drama. They even prefer them over other popular entertainment products like Hollywood movies and Turkish series. Accordingly, K-pop and K-drama earned a great acceptance in the Algerian society. The huge percentage of 99.3\% of participants who prefer Hallyu entertainment products rather than Algerian ones proves that the Korean Wave's entertainment gets widely spread and continues to gain popularity in Algeria as Figure 1 shows through years of start. Results demonstrate the phenomenal influence of the Korean Wave on $98.5 \%$ of 139 participants. The majority of them declared being influenced in two aspects: language and behavior. They want to learn the Korean language with its letters that are not even Roman like English or French. According to them, Korean, unlike it seems, it is easy to learn. It is also a rich language with an expressive lexis. Most participants revealed that they are influenced to the extent that they started using Korean words through their daily discourse with both people who understand and those who do not understand them. Most of them use these Korean words basically because they find them more expressive to clarify their point and feel more into the Korean culture they are interested in. They also use them in order to practice speaking Korean, as an important step of language learning, and for the sake of making a code between them and their fandom mates when they do not want others to understand what they say. On the other hand, participants mainly use some Korean words unconsciously with people who do not understand them and sometimes they use them when they feel more expressive, i.e., they can express the exact intended meaning with these words, even if their interlocutor does not have a clue about them.

Hallyu impact in Algeria reached the phase of participants sending and receiving reply SMSs in Korean to and from their pals. Participants declared that they even write random thoughts in Korean in their diaries or copybooks. This trait signifies that they started "thinking" in Korean. Regarding what they claimed that the Korean language is expressive and considering the Sapir-Whorf Hypothesis, the Korean language semantic categories have influenced their cognitive categories. The influence of Korean took place on participants' cognitive thoughts and developed them with its expressive lexis with which they started thinking. This fact denotes that Korean with its kinship terms and cultural vocabulary became part of their lives. Moreover, many participants revealed that they use some proverbs translated from Korean into their mother tongue, Algerian Arabic. This cultural feature is also a proof that Hallyu transmitted its culture into most obsessed fan participants' intellectual conception of life. Coming to inside jokes, a person from outside the fandom or even a fan who does not go deep into their favorite artists' daily activities through social media will not understand them when other fans use them. The majority of participants agreed that they use inside jokes with their pals. This shows that their obsession with K-pop and K-drama enhanced their ability to adopt strange terms and expressions most of which are not linguistically authentic, either semantically, morphologically, or both. Naming phone contacts in Korean is also an advanced phase of Hallyu influence. Most of Korean numerous kinship terms like "noona" (a boy's older sister/friend) do not exist in other languages including Algerian Arabic. Therefore, participants prefer naming their contacts in Korean in order to specify contacts, accurately. Hallyu's specific language also includes English terms that are dedicated to it. Participants assured that they use such terms like comeback, visual, bias, golden maknae, etc. These English terms that only Koreans use with different meanings are called "Konglish" (Korean English). Koreans' pronunciation of English sounds is influenced by their mother tongue's phonetic and phonological characteristics. Similar to Arabs who alter the sound $/ \mathrm{p} /$ with $/ \mathrm{b} /$ and the sound $/ \mathrm{v} /$ with $/ \mathrm{f} /$ because these sounds do not exist in Arabic, Koreans change the 
sounds $/ \mathrm{f} /$ to $/ \mathrm{p} /, / \mathrm{z} /$ to $/ 3 /, / \mathrm{r} /$ to $/ \mathrm{l} /, / \mathrm{l} /$ to $/ \mathrm{r} /, / \mathrm{v} /$ to $/ \mathrm{b} /, / \theta /$ to $/ \mathrm{s} /$, and $/ \mathrm{s} /$ to $/ \mathrm{s} /$ (in some positions). They also add the near-close central unrounded vowel $/ \mathrm{r} /$ that is pronounced "eu" at the end of English words that lack an ending vowel (e.g., hand) or end with the vowel "e" (e.g., life) to which "eu" in Korean is an equivalent vowel. These phonological features occur through participants' pronunciation of some English sounds. The percentage of uninfluenced participants is just a bit higher than influenced ones, which makes the existence of this influence undeniable. Through reviewing data, the influence of Korean pronunciation of English sounds on participants' pronunciation is not dependent on how much time or how many years they spend watching K-pop and K-drama. For example, four participants who got into Hallyu world in 2008 disagreed on this influence while six participants who started in 2014 agreed on it. Instead, the Influence of Koreanized English pronunciation depends on whether a fan accepts it or not and whether they have pals to practice Hallyu language with or not.

In terms of Corpus Planning, participants' discourse includes Korean and English words that are either modernized, graphitized, or both. These words are as follows:

Korean words (see Table 2)

Table 2

Korean Words to Which Corpus Planning Applies

\begin{tabular}{|c|c|c|c|}
\hline Word & $\begin{array}{l}\text { Meaning } \\
\text { Corpus planning aspect }\end{array}$ & Modernization & Graphization \\
\hline Aegyo & Cute gestures with kind of baby talk that show innocence & $\mathrm{X}$ & \\
\hline Ahjumma & A honorific nickname for a woman who is at a mother age & $\mathrm{X}$ & \\
\hline Ahjusshi & A honorific nickname for a man who is at a father age & $\mathrm{X}$ & \\
\hline Chaebol & A wealthy person & $\mathrm{X}$ & \\
\hline Daebak & $\begin{array}{l}\text { Expresses impression with someone/something or reaction to a great } \\
\text { victory }\end{array}$ & $\mathrm{X}$ & \\
\hline Dongseang & Younger brother/sister & $\mathrm{X}$ & \\
\hline Hul & Expresses dissatisfaction or awkwardness & $\mathrm{X}$ & \\
\hline Hwaiting & Korean equivalent to "fighting" that is said to support oneself or others & $\mathrm{X}$ & $\mathrm{X}$ \\
\hline Kul & Means "honey" and expresses agreement on a deal or a suggestion & $\mathrm{X}$ & \\
\hline Uljjang & $\begin{array}{l}\text { "Ul" is short for "eolgul," meaning "face" and jjang means "best". It } \\
\text { refers to a very handsome/beautiful famous person on Internet }\end{array}$ & $\mathrm{X}$ & $\mathrm{X}$ \\
\hline Sasaeng & A dangerous fan who invades stars' privacy and is able to kidnap them & $\mathrm{X}$ & \\
\hline Sogaeting & $\begin{array}{l}\text { "Sogae" means introducing while "ting" is a short form of "dating" } \\
\text { meaning "blind date" as a whole }\end{array}$ & $\mathrm{X}$ & $\mathrm{X}$ \\
\hline Tsundere & A warm-hearted person who acts cold and charismatic from outside & $\mathrm{X}$ & \\
\hline
\end{tabular}

English words (see Table 3)

Table 3

English Words to Which Corpus Planning Applies

\begin{tabular}{|c|c|c|c|}
\hline English Word & $\begin{array}{l}\text { Meaning } \\
\text { Corpus planning aspect }\end{array}$ & Modernization & Graphization \\
\hline All-kill & A song on top of all major charts in Korea & $\mathrm{X}$ & \\
\hline Antis & $\begin{array}{l}\text { Short form of anti-fans and refers to people who show hatred for an idol } \\
\text { group or a single star through social media or real threats }\end{array}$ & $\mathrm{X}$ & $\mathrm{X}$ \\
\hline Bias & Favorite member in a group & $\mathrm{X}$ & \\
\hline Bias wrecker & The second favorite member in a group who may take the first place & $\mathrm{X}$ & \\
\hline Comeback & A K-pop single artist's or a group's new album & $\mathrm{X}$ & \\
\hline
\end{tabular}


(table 3 continued)

\begin{tabular}{|c|c|c|c|}
\hline English Word & $\begin{array}{l}\text { Meaning } \\
\text { Corpus planning aspect }\end{array}$ & Modernization & Graphization \\
\hline Concept & The outfit or look that goes with the theme of each album & $\mathrm{X}$ & \\
\hline Fan Chants & $\begin{array}{l}\text { Mixed melodies with backing vocals that fans sing along with the } \\
\text { performance they attend }\end{array}$ & $\mathrm{X}$ & \\
\hline Fan Service & Anything stars do that is pleasant for fans & $\mathrm{X}$ & \\
\hline Fanboy/Fangirl & $\begin{array}{l}\text { A boy/girl fan who has passionate emotional attitude toward their bias. It } \\
\text { is used as a verb, too }\end{array}$ & $\mathrm{X}$ & \\
\hline Jams & $\begin{array}{l}\text { Originated from the Korean word "jaem" (fun) as a pun and refers to } \\
\text { sense of humor }\end{array}$ & & $X$ \\
\hline Jungshook & $\begin{array}{l}\text { Inspired from BTS Jungkook's shook face and is used by fans to express } \\
\text { astonishment }\end{array}$ & & $\mathrm{X}$ \\
\hline Hyung Line & The oldest members in a group who are almost peers & $\mathrm{X}$ & \\
\hline Maknae Line & The youngest members in a group who are nearly at the same age & $\mathrm{X}$ & \\
\hline Melo & Short for "Melodrama" & $\mathrm{X}$ & $\mathrm{X}$ \\
\hline Netizen & Daily Internet users who notice everything stars do and are big critics & $\mathrm{X}$ & \\
\hline Infires & $\begin{array}{l}\text { Originated from the verb "inspires" and signifies inspiration that could } \\
\text { put someone's brain on fire }\end{array}$ & & $\mathrm{X}$ \\
\hline Selca & Abbreviation for "Self-camera" meaning "selfie" & $\mathrm{X}$ & $\mathrm{X}$ \\
\hline Stan & a passionate fan and is used as a verb like to stan a celebrity & $\mathrm{X}$ & \\
\hline Trash & $\begin{array}{l}\text { A fan who cannot choose their best member because they love all } \\
\text { members of the group }\end{array}$ & $\mathrm{X}$ & \\
\hline V Line & V-shaped jaw line & $\mathrm{X}$ & \\
\hline Virus & A person who spreads happiness and joy & $\mathrm{X}$ & \\
\hline Visual & Refers to the most handsome/beautiful member in the group & $\mathrm{X}$ & \\
\hline Stahb it & Wrong pronunciation of "stop it" & & $\mathrm{X}$ \\
\hline Satoori & Rural dialect spoken in South Korean countryside & $\mathrm{X}$ & \\
\hline Skinship & Refers tophysical contact & $\mathrm{X}$ & $\mathrm{X}$ \\
\hline Triple Crown & $\begin{array}{l}\text { An award given to a K-pop group when their song reaches the top on all } \\
\text { three of Korea's major music shows: M(net)Countdown, Inkigayo, and } \\
\text { Music Bank }\end{array}$ & $\mathrm{X}$ & \\
\hline
\end{tabular}

The words "jams", "jungshook", "infires", and "stahb it" are only graphitized not modernized because not all Hallyu fans use them but only BTS fans, A.R.M.Y., use them.

\section{Conclusion}

This study on the case of Algerian Hallyu fans almost encompasses all the aspects of their linguistic attitude towards Hallyu. It includes vocabulary expansion with loan terms from Korean and English that they use in their speech and with which they name their phone contacts, the use of translated proverbs from Korean culture, inside jokes, and the influence on their pronunciation of some English sounds.

As an aspect of language change at the community level, Corpus Planning takes place on participants' language but only with two types: Graphization through which some words' spelling is partly changed and Modernization through which many words are added to participants' glossary in order to meet their needs for an accurate communication tackling Hallyu. According to participants, Hallyu fans in Algeria begin with using Korean words in their speech and then they start using English words that are specific to K-pop and K-drama and naming their phone contacts with Korean terms of endearment and kinship. They also use some translated sayings and proverbs from Korean into their mother tongue. After getting more into Hallyu entertainment products, they reach an advanced level of influence that is thinking in Korean. At this level, they start writing 
notes and random thoughts in Korean on paper. Furthermore, they start using inside jokes that are mainly based on non-existing words or words with odd orthographic and semantic characteristics. These words are often unintentionally created by their favorite idols or stars due to their lack of English proficiency. Hallyu influence makes even non-English speaking fans learn and speak English regarding that K-pop and K-drama are two-language based entertainment products: Korean and English. Finally, Hallyu influence appears on their pronunciation of some English sounds. Briefly, almost all Hallyu influence aspects on participants are inevitable, especially those of adopting loan terms and changing spelling forms of some words.

\section{Recommendations}

This thesis analyses Hallyu International fans' language as a kind of fandom language, which is an important aspect of the domain of Conversational Analysis. Therefore, it contributes to this domain by inviting other researchers to conduct similar studies about the linguistic influence of the Korean Wave in their societies. Several studies about Hallyu fandom's language will prove its global impact and the partial role of Corpus Planning in it. Thus, Hallyu language will serve as a sample for Corpus Planning studies and as a guise of the influence of entertainment products, especially foreign ones, on language of fans. A gender-comparative study could be undertaken on Hallyu influence on International fans' language in order to develop this research domain. Other researches about Anime or Harry Potter and such fandom languages could take this thesis as a type of fandom discourse.

\section{References}

Baldauf, R. B. (1989). Language planning: Corpus planning. Annual Review of Applied Linguistics, $10,3$. doi:10.1017/s0267190500001173

Chami, A. (4/12/2009). A historical background of the linguistic situation in Algeria (pp. 387-395). Retrieved from file://C:/Users/Administrator/Downloads/Pages de Al_mawaqif_04_2009-6(3).pdf

Choechoiblyeog. (2017). Jeonsegyehanlyupaen 6cheonman myeong.Daehanminguginguttwieoneom-eossda (60 million Hallyu fans from all over the world... Surpassing Korea's population). Retrieved 13 October, 2017 from http://www.yonhapnews.co.kr/ bulletin/2017/01/25/0200000000AKR20170125099200371.HTML

Estavillo, M. (2012). South Korea bolsters copyright strategy in K-pop crazy states-intellectual property watch. Retrieved 22 February, 2017 from http://www.ip-watch.org/2012/12/14/south-korea-bolsters-copyright-strategy-in-k-pop-crazy-states/

Fishman, J. (1987). Ideology, society \& language. Ann Arbor: Karoma Publishers.

Frog-kun. (n.d.). (2013). How does the anime fandom affect how you learn and perceive the Japanese language? Retrieved 20 February, 2017 from https://frogkun.com/2013/08/08/how-does-the-anime-fandom-affect-how-you-learn-and-perceivethe-japanese-language/

Fukunaga, N. (2006). "Those Anime Students": Foreign language literacy development through Japanese popular culture. Journal of Adolescent \& Adult Literacy, 50(3), 206-222. doi:10.1598/jaal.50.3.5

Haugen, J. (1983). The impact of corpus planning on bilingual dictionaries.

Hong, E. (2014). The birth of Korean cool. London: Simon \& Schuster.

Koreaboo. (2015). These 11 wise Korean proverbs could transform your life-Koreaboo. Retrieved 22 October, 2017 from http://www.koreaboo.com/uncategorized/these-11-wise-korean-proverbs-could-transform-your-life/

Korean Wave. (n.d.). In Wikipedia. Retrieved 4 April, 2017 from https://en.wikipedia.org/wiki/KoreanWave

K-pop for Beginners. (2017). What is K-pop? Retrieved 1 October, 2017 from http://kpopforbeginners. weebly.com/what-is-kpop.html

Leung, S. (2012). Catching the K-pop wave: Globality in the production, distribution, and consumption of South Korean popular music. New York: Vassar College.

Otmazgin, N., \& Lyan, I. (2013). Hallyu across the desert: K-pop fandom in Israel and Palestine. Cross-Currents: East Asian History and Culture Review. Retrieved 18 February, 2017 from http://cross-currents.berkeley.edu/e-journal/issue-9 
Potayroi. (2014). Fandom as a discourse community (p. 123). Retrieved 21 February, 2017 from https://thansong123.wordpress.com/2014/04/24/fandom-as-a-discourse-community/

Ravina, M. (2009). Introduction: Conceptualizing the Korean wave (pp. 3-9). Emory University: Southeast Conference of the Association for Asian Studies. Retrieved 3 October, 2017 from http://www.uky.edu/Centers/Asia/SECAAS/Seras/ 2009/02 Ravina_2009.pdf

Ryoo, W. (2007). Globalization, or the logic of cultural hybridization: The case of the Korean wave. Conference Papers International Communication Association, 1-27. Retrieved from Communication \& Mass Media Complete Database.

Smith, M. (2015). Is Harry Potter fandom real?-Literacy \& Discourse. Retrieved 21 February, 2017 from https://medium.com/literacy-discourse/is-harry-potter-fandom-real-21b5b407f3c8\#.hz9khas7n

Trish. (2014, July 27). International K-pop fans: Mind and Seoul. Retrieved 17 February, 2017 from https://c32tmontealto.wordpress.com/2014/07/27/international-kpop-fans-mind-and-seoul-2/

Verbalink.com. (n.d.). Citation un site web-cite this for me. Retrieved 22 October, 2017 from https://verbalink.com/ articles/whycan-t-some-words-be-translated

Wright, A. (2011). The language of fandom: From Twihards to Tolkienites-Oxford words blog. Retrieved 24 January, 2017 from https://blog.oxforddictionaries.com/2011/11/18/the-language-of-fandom/ 